\title{
Cash Transfers and Migration: Theory and Evidence from a Randomized Controlled Trial ${ }^{*}$
}

\author{
Jules Gazeaud $^{\dagger} \quad$ Eric Mvukiyehe ${ }^{\ddagger} \quad$ Olivier Sterck $\S$
}

November 24, 2020

\begin{abstract}
Will the fast expansion of cash-based programming in poor countries increase international migration? Theoretically, cash transfers may deter migration by increasing its opportunity cost, or favor migration by relaxing liquidity, credit, and risk constraints. This paper evaluates the impact of a cash-for-work program on migration. Randomly selected households in Comoros were offered up to US $\$ 320$ in cash in exchange for their participation in public works projects. We find that the program increased international migration by 38 percent, from $7.8 \%$ to $10.8 \%$. The increase in migration appears to be driven by the alleviation of liquidity and risk constraints.
\end{abstract}

JEL Classification: J61, O12, O15, F22

Keywords: Migration, Cash Transfers, Financial Constraints, Risk-aversion

\footnotetext{
${ }^{*}$ We thank the editor and the three anonymous referees for their very valuable comments. We also thank Samik Adhikari, Cátia Batista, Simone Bertoli, Michael Clemens, Federica Esu, Jeremy Foltz, Douglas Gollin, Flore Gubert, John Loeser, David McKenzie, Ricardo Mora, Elisabeth Sadoulet, Cyrus Samii, Olivier Santoni and participants at numerous seminars and conferences for helpful feedback and suggestions. We are grateful to FADC staff, in particular Doulfat Dilkamal and Bahtine El-Maarouf, for their constant support and collaboration. During survey implementation, we were privileged to work with INSEED and an excellent team of enumerators. We are particularly indebted to Mariama Abdallah, Emile Bourdonnais, Kiwamiddine Chibaco, Bendjadid Moissulu, Mounir Moustoidrane, Mohamed Nourdine, Anfane Oussoufa, Quentin Roy, Houssam Siaka, Djaffar Soudjah and Faissoil Youssouf for wonderful fieldwork. Finally, we express our deepest gratitude to all households who participated to our surveys. This research would have not been possible without their collaboration. The computational reproducibility of the results has been verified by DIME analytics. Funding come from $\mathrm{i} 2 \mathrm{i}$ - an umbrella facility fund supported by the World Bank and DFID with the objective of expanding the use of IE across the developing world, particularly in areas that have traditionally been under-evaluated - and the Jobs Umbrella Trust Fund, which is supported by DFID and the Governments of Norway, Germany, Austria, the Austrian Development Agency, and the Swedish International Development Cooperation Agency.

${ }^{\dagger}$ NOVAFRICA, Universidade Nova de Lisboa. E-mail: jules.gazeaud@novasbe.pt

‡DIME, The World Bank. E-mail: emvukiyehe@worldbank.org

§ ODID, University of Oxford. E-mail: olivier.sterck@qeh.ox.ac.uk
} 


\section{Introduction}

International migration is a defining issue of our time. The number of international migrants worldwide has grown by 57\% between 2000 and 2019, from 173 million to 272 million (United Nations, 2019). More than 750 million people aspire to migrate to another country if they had the opportunity (Esipova et al. 2018). Against this background, an intense debate is raging between those portraying migrants as a threat and those arguing that the current migration policies are inhumane, unfair, or inefficient (Clemens, 2011; Baele and Sterck, 2015; Keen and Andersson, 2018). These trends are profoundly reshaping the migration and development policies of Western countries and contributing to the rise of populism in Europe and in the US (Halla et al., 2017; Mayda et al., 2018; Dustmann et al., 2018). In the wake of the "migration crises" in Europe and in the Americas, aid budgets were redirected towards addressing the root causes of irregular migration (Clemens and Postel, 2018) and supporting job creation in origin countries (Giambra and McKenzie, 2019).

Another transformation is concurrently reshaping development and humanitarian assistance. In view of the mounting evidence of the positive and wide-ranging effects of conditional and unconditional cash transfers (Arnold et al., 2011; Bastagli et al., 2016), cash-based programming is rapidly becoming the benchmark modality of social assistance. In 2015, as many as 130 low- and middle-income countries had at least one non-contributory unconditional cash transfer (UCT) program and 63 countries that had at least one conditional cash transfer program, up from two countries in 1997 (Honorati et al. 2015). Embodying this paradigm shift, the World's major humanitarian donors and aid organizations endorsed the Grand Bargain at the World Humanitarian Summit in May 2016, which calls for increased use of cash-based programming to "deliver greater choice and empowerment to affected people and strengthen local markets". The Covid-19 pandemic has accelerated this trend; as of May 22 2020, 161 new cash-transfer programs had been introduced in 104 countries in response to the pandemic (Gentilini et al., 2020).

Do cash transfers foster or deter international migration? Our paper addresses this 
question theoretically and empirically.

Theoretically, we identify four main channels through which cash transfer interventions could affect migration. First, cash transfers relax the budget constraint and can therefore facilitate the migration of households facing a liquidity constraint (liquidity channel). Second, cash transfers that are conditional on remaining in the origin country (e.g. to participate in public works) increase the opportunity cost of migrating and can therefore reduce migration (opportunity-cost channel). Third, the prospect of future cash transfers can be used as a collateral by households in order to facilitate access to credit and thereby finance migration upon their selection into the cash-transfer program (collateral channel). Finally, as migration is a risky investment, cash transfers can encourage the migration of individuals whose preferences are characterized by decreasing absolute risk aversion (DARA) while restraining those characterized by increasing absolute risk aversion (IARA) (risk-aversion channel).

Empirically, we study the impact on international migration of a randomized cashfor-work intervention targeted at very poor households in Comoros. The cash-forwork program is conceptually equivalent to a cash transfer program that is conditional upon participating in public works. Between the baseline and endline surveys, beneficiary households received up to the equivalent of US\$320 in cash conditional on their participation in public work activities ${ }^{1}$ We assess the effects of the program on international migration.

Migration patterns are salient in Comoros, especially towards Mayotte - the neighboring French Island. A mix of geographical proximity and economic disparities causes many Comorians to migrate to Mayotte. Comorian migrants typically use small fishing boats called kwassa-kwassa to reach Mayotte. The journey is both risky and costly, especially since 1995, after France established visa requirements for Comorians traveling to Mayotte, hence forcing aspiring migrants to use smugglers and illegal sea routes.

We find that cash windfalls had a sizable and positive impact on migration to May-

\footnotetext{
${ }^{1}$ Throughout the paper, we use an exchange rate of $430 \mathrm{KMF}$ (Comorian Franc) for one dollar.
} 
otte. The migration rate of beneficiary households increased by about 38 percent, from $7.8 \%$ to $10.8 \%$. We estimate an average income elasticity of migration of about 1 . We find suggestive evidence that the liquidity and the risk-aversion channels drive the results. In line with the liquidity channel, the effect of the cash transfers on migration to Mayotte is concentrated within households with low levels of savings at baseline. We also find that the effect of the cash transfers on migration is concentrated within households that are more risk-averse at baseline, which suggests that cash transfers reduce risk aversion and thereby foster risky migrations.

By contrast, the opportunity cost channel seems irrelevant in this study. Indeed, beneficiary households were entitled to send the adult of their choice to public works and our results show that workers and migrants are actually very different. This suggests that the program did not increase the opportunity cost of individuals who were likely to migrate. The collateral channel also seems negligible in our study. The cashfor-work program had no significant effect on debt at baseline and at endline. The increase in migration generated by the program was mainly financed through savings and transfers from relatives. If the collateral channel were operating, the effect of the cash transfer program should have appeared soon after households learned that they were selected into the program, as in the study of Angelucci (2015) on MexicoUS migration. In contrast with this prediction, we find that the effect of transfers on migration takes time to appear, which is consistent with the liquidity channel.

Our paper makes an important contribution to the literature on the effects of cashbased programming on international migration. Experimental evidence is limited to the effect of Mexico's Progresa program on migration to the US Adhikari and Gentilini. 2018). While Stecklov et al. (2005) find that the Progresa program reduced overall migration to the US, Angelucci (2015) suggests that the program increased labor-induced migration to the US by relieving the credit constraints of eligible households. A few studies also explored the effects of social assistance programs on rural-urban migration in middle-income countries. While pension programs seem to promote labor migration for young adults in recipient households (Ardington et al., 2009: Eggleston 
et al., 2016), India's NREGA cash-for-work program reduced short-term migration by increasing the opportunity cost of migrating (Imbert and Papp, 2019). The present study addresses the need for more robust evidence on the effects of cash transfers on international migration outside the Mexico-US context, and provides theoretical and empirical evidence on the mechanisms at play.

More generally, our research contributes to the literature on the determinants of international migration, adding new empirical evidence on the relationship between income and migration. Researchers using macro-level data have identified a clear inverted U-shaped relationship between income and migration rates (Dao et al., 2018, Sterck, 2019). Micro-level evidence is, however, far less conclusive, and mostly focuses on middle-income countries (Clemens et al., 2014). In line with Bazzi (2017), we find that a positive income shock affecting very poor households increases international migration by relaxing liquidity constraints. In contrast with the findings of Kaestner and Malamud (2014) and Angelucci (2015), we find no evidence of an alleviation of credit constraints.

Our paper also talks to the body of literature linking risk and migration, by showing that risk aversion may moderate the effect of cash transfers on migration. Risk is inherent to the decision to migrate. On one hand, migration is a costly investment with uncertain but potentially large returns (McKenzie et al., 2010; Clemens, 2011; Gibson and McKenzie, 2012; Bryan et al. 2014) ${ }^{2}$ On the other hand, staying home also entails some degree of risk, especially in contexts affected by political instability, insecurity, natural hazards, and poor social security. Migration can be optimal ex-ante to avoid these risks, or ex-post to cope with the negative consequences of a shock (Kleemans, 2015: Kleemans and Magruder, 2017; Mahajan and Yang, 2017). Households can also self-insure against some risks by financing the migration of one of their members (Dustmann et al., 2017; Morten, 2019), especially since migration can crowd-in risk sharing within communities (Meghir et al., 2019). Empirical studies in a wide va-

\footnotetext{
${ }^{2}$ Recent evidence suggests that the risks associated with migration are often misestimated by potential migrants, and that risk perceptions are strongly correlated with their willingness to migrate (Bah and Batista, 2018: Batista and McKenzie, 2018: Shrestha, 2019b).
} 
riety of settings conclude that risk aversion is strongly and negatively associated with mobility (Jaeger et al., 2010; Gibson and McKenzie, 2011; Akgüç et al., 2016; Goldbach and Schlüter, 2018; van Huizen and Alessie, 2019). In line with this literature, our results suggest that risk-averse households are less likely to migrate in the absence of transfers, but more likely to respond to the treatment.

Finally, our research contributes to the literature on the effects of cash-based programming. A substantial body of research documents direct positive impacts of conditional and unconditional cash transfers on nutrition, assets, education, health, and psychological wellbeing (see e.g. Bastagli et al. 2016; Haushofer and Shapiro 2016: Millán et al. 2019: MacPherson and Sterck 2019: Cahyadi et al. 2020) ? $^{3}$ The cash-transfer literature also identified both positive and negative externalities on non-beneficiaries through transfers or market effects (see e.g. Angelucci and De Giorgi 2009: Cunha et al. 2018; Filmer et al. 2018; D'Aoust et al. 2018; Delius and Sterck 2020). Our results suggest that migration is an additional, understudied, source of externality affecting host populations. Our paper also contributes to the literature on public works programs, and in particular on cash-for-work programs (Gehrke and Hartwig, 2018). To our knowledge, our study is the first to provide experimental evidence on the effect of a cash-for-work program on international migration.

The remainder of the paper is structured as follows. Section 2 discusses the theoretical channels through which cash transfers can affect migration. Section 3 provides background information on migration in Comoros and on the Comoros Social Safety Net Program (SSNP). Section 4 describes the identification strategy and the data. Section 5 presents the results. Section 6 explores possible channels of impact. Section 7 concludes.

\footnotetext{
${ }^{3}$ The effect of cash transfers on labor market-related outcomes depends on the context and on the conditions attached to transfers (Baird et al. 2018).
} 


\section{Theory}

We study theoretically how a cash transfer intervention can affect migration. For the sake of brevity, this section focuses on intuitions. A formal model is presented in online appendix $B$

We identify four main channels through which a cash transfer intervention could affect migration.

The liquidity channel The main effect of unconditional cash transfers is to ease the budget constraint of households. As a result, cash transfers allow the migration of households that are liquidity constrained without cash assistance but able to finance migration when they benefit from the additional income.

Opportunity cost channel Cash transfers that are conditional on presence in the origin country increase the opportunity cost of migrating and may therefore reduce migration. In the case of a cash-for-work program that is conditional on all household members working in the origin country, for example, households that would have been migrating without the conditionality are expected to cancel or postpone migration if the value of the cash transfer is larger than the cost of canceling or delaying migration. The opportunity cost channel affects the decision of households able to finance migration without cash transfers and for which the wage differential is lower than the value of the transfers.

Collateral channel Unconditional cash transfers can facilitate access to credit and thereby increase the migration of credit constrained households as soon as they are selected to benefit from cash transfers (and even before they receive any cash). Three mechanisms can be at play. First, the maximum amount that households can borrow is likely to increase as soon as households are selected to benefit from the unconditional cash transfers, as the guaranteed future income stream can play the role of a collateral. As a result, more households may be able to finance migration through borrowing. 
Second, interest rates on loans are likely to decrease because the risk of default is reduced by the increase in future income. With reduced interest rates, more households may find it optimal to borrow to finance migration. Finally, if cash transfers are administered by a micro-credit organization, credit constraints may also be relaxed thanks to the greater proximity between beneficiaries and the micro-credit organization.

Risk-aversion channel Migration is a risky investment and, in the presence of risk, households' degree of risk aversion influence their decision-making process. Risk aversion means that their utility function is concave, which implies that households dislike zero-mean risks. In the presence of risk and risk aversion, an unconditional cash transfer not only impacts the budget constraint of households (liquidity channel), but also the expected utility returns from migration. The direction of this latter effect depends on how risk aversion varies with income. If the utility function of households is characterized by decreasing absolute risk aversion (DARA), an unconditional cash transfer increases the expected utility returns from investing in migration. By contrast, if their utility function is characterized by increasing absolute risk aversion (IARA), the unconditional cash transfer reduces the expected utility returns from investing in migration. Experimental and empirical evidence supports the hypothesis of decreasing absolute risk aversion (see e.g. Dohmen et al. 2011 and Guiso and Paiella 2008).

In summary, theory suggests that cash transfers may relax liquidity, credit, or risk constraints and therefore encourage migration. But cash transfers may also increase the opportunity cost of migrating if they are conditional on presence in the origin country. More details on the four channels are provided in online appendix $B$. 


\section{Background of the cash-for-work program}

\subsection{Context}

The Comoro archipelago consists of four islands located in the Mozambique Channel, between Mozambique and Madagascar (see Figure 1). Strong ties unite the four islands. During the French colonisation, they were unified under a single administration and placed under the authority of the French colonial governor of Madagascar ${ }^{4}$ However, during the 1974 independence referendum, Mayotte voted to remain politically a part of France while other islands voted for independence and formed the Union of Comoros (Comoros henceforth) ${ }_{5}^{5}$ Since then, Mayotte has been continuously administered by France and even became a French overseas department in 2011.6 Socioeconomic conditions have steadily improved in Mayotte while stagnating in neighboring Comorian islands. Today, the GDP per capita in Mayotte is more than 10 times that of Comoros:7Poverty in Comoros is high with 42 percent of the population living with incomes below US\$1.90 per day, and one-third of all children under five years of age suffering from chronic malnutrition.

In order to control the migration of Comorians to Mayotte, France issued strict visa requirements in 1995. However, illegal sea routes and human smuggling emerged such that the flow of Comorian migrants never stopped to date. Illegal migration to Mayotte is widespread and virtually all Comorians know the migration technology. The migration route is depicted in Figure 1. Migrants typically converge to the south-east of Anjouan and then use small fishing boats, called kwassa-kwassa, to reach Mayotte. Thousands of Comorians have died on this often overlooked migration route (Sénat, 2001, 2008, 2012; Le Monde, 2017). However, because the majority of migrant

\footnotetext{
${ }^{4}$ People share a similar language, Shikomori, and are predominantly Muslim. They also have similar social structures such as a matrilineal system shaped by the informal institution of the Grand mariage - a determinant of social status whose completion greatly increases one's standing in society. Census data from 2015 suggest that 42 percent of Mayotte population was born in Comoros (Marie et al. 2017).

${ }^{5}$ See Blanchy (2002) for a discussion on why the people of Mayotte decided to remain French.

${ }^{6}$ France has vetoed several United Nations Security Council resolutions that would affirm Comorian sovereignty over Mayotte.

${ }^{7}$ In 2017, the GDP per capita of Comoros in current US\$ was US\$1312 (World Bank data), while the GDP per capita of Mayotte was US\$13,050 USD (authors' calculation based on EUROSTAT, INSEE, and OECD data).
} 
Figure 1: Migration route to Mayotte

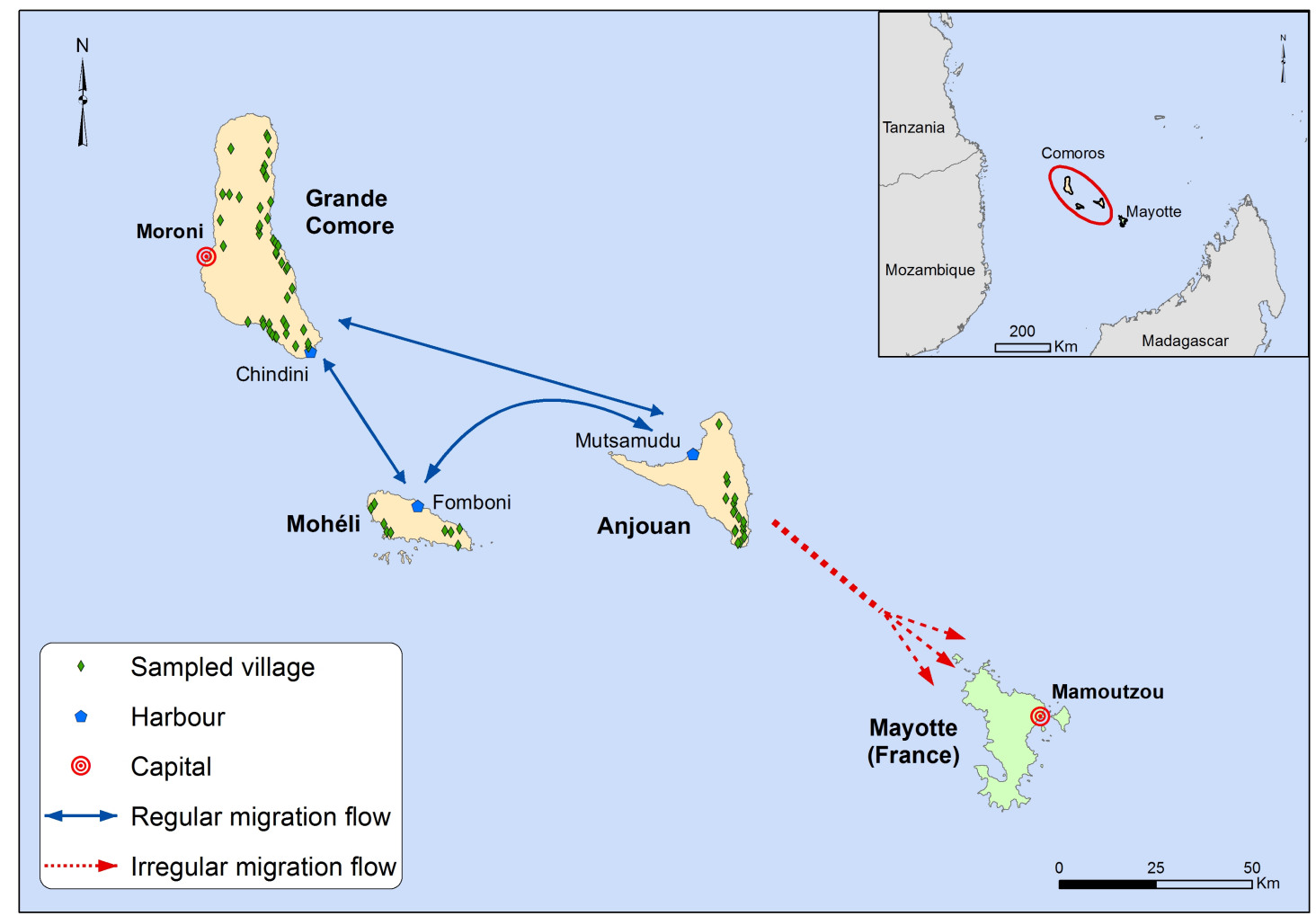

Source: Authors' elaboration

deaths probably go unrecorded, there is no credible estimate of the number of fatalities.

Our qualitative survey provides sobering evidence on these migration flows. All respondents reported that using a kwassa from Anjouan to Mayotte is the only migration technology available to them. They perceive it as particularly risky and have many friends or relatives who died from a migration attempt to Mayotte (often in recent years). As a respondent put it: "There is only one way to go to Mayotte, it is to take a kwassa. Only people with a normal situation can travel by plane or boat. The journey is so difficult and risky. I know many people who have lost their lives in this sea. The number of people in this village who died because of Mayotte is uncountable". Migration costs are relatively high and typically depend on the number of migrants in the kwassa (the higher the number of individuals, the lower the price of the journey). They can go from a minimum of US\$230 (if the kwassa is overloaded) to a maximum of US\$1150 (for what is often called a "VIP kwassa", that is, a kwassa with only a few migrants) 8 Migrants

\footnotetext{
${ }^{8}$ As a comparison, the median annual consumption per capita in our sample is US $\$ 460$.
} 
generally finance these costs through their savings, the sale of livestock, and the help of relatives. In addition to the risk of dying en route, migrants face substantial risks of being arrested and expelled by the French police. 9 Several respondents alluded to these risks and possible consequences, as reflected in this quote: "Sometimes, we sell high-value properties to pay transportation costs, and unfortunately we get arrested by the police and have to start again from scratch. In these cases, we are in a depressing situation with nameless regrets".

\subsection{The Comoros Social Safety Net Program (SSNP)}

The SSNP was initiated in 2015 by the Government of Comoros in collaboration with the World Bank. Prior to running this program, the implementing agency had successfully implemented a variety of World Bank projects, including similar cash-for-work programs. The objectives of the SSNP were to improve poor communities' access to safety net and nutrition services, smooth consumption, and support the development of productive activities.

The main component of the program provided cash-for-work (CFW) opportunities to poor households, i.e. cash transfers conditional on their participation in public works such as reforestation, water management, and terracing. Beneficiary households were entitled to send one able-bodied adult of their choice to public works. Households with no able-bodied adults received unconditional cash transfers. Cashfor-work activities were implemented in periods of 20 days with payments made at the end of each period by a local micro-credit institution known as MECK. The wage rate was US\$2.3 for four hours of work per day. Households were informed during the information campaign that the program would last three years and that beneficiaries would receive nine rounds of CFW overall. The program had some implementation delays, and at the time of the follow-up survey beneficiaries received between three and seven rounds of CFW 10

\footnotetext{
${ }^{9}$ According to official French statistics, each year, more than 20,000 illegal migrants are deported to Comoros.

${ }^{10}$ The number of rounds of cash-for-work activities varies across villages because of the progressive
} 
A total of 69 rural villages were selected by the implementing agency to receive the intervention. The implementing agency selected the poorest villages using the poverty map drawn up by the Comorian national institute of statistics (known as INSEED) in 2003/2004 (Table A1 in appendix). Within villages, the selection of beneficiaries was done in several steps. First, self-targeting was expected because of the labor requirement, the (non-monetary) front costs of applying, and the low wage rate for the public works. Second, village committees pre-selected the poorest 60 percent households in their villages using four equally-important criteria: (i) the household head attended primary school at most; (ii) the household has at least four children below 15 years of age; (iii) the household has children aged between 6 and 14 who are not enrolled in school; (iv) the household has no agricultural field. As there were more pre-selected households than CFW opportunities, the selection of beneficiaries lastly relied on a public lottery organized by village committees and the implementing agency.

\section{Experimental design and data}

\subsection{Empirical strategy}

The impact evaluation has been designed as a multi-level randomized controlled trial. At the household level, beneficiaries were randomly selected from the group of $60 \%$ households that had been pre-selected by local committees (see Section 3.2 above). At the cluster level, villages were randomly assigned to receive either a low or high intensity treatment, in order to assess indirect effects. Specifically, in each village, one third or two thirds of the pre-selected households were randomly assigned to the treatment. This means that overall $20 \%$ or $40 \%$ of eligible households were ultimately selected 11

roll-out of the program (more details in Section 4.2).

${ }^{11}$ The evaluation design also had a gender component. Households with both male and female potential workers chose one individual of each gender to be the potential beneficiary of the program. Then for these households, the gender of the main worker was randomly selected. In practice, however, the rule that the main worker should participate in the works was never enforced: households could send the person of their choice and, ultimately, the majority of households sent a female worker as the daily wage rate was mostly attractive for them. For this reason, the analysis of the gender randomization face 
These two levels of random assignment are core to the empirical strategy. Because of the random assignments, households and villages with different treatment conditions are similar in expectation in every respect except for their treatment status. Any difference in outcome between treatment and control groups after the program can thus be attributed to the difference in treatment. Below, we provide more details on how we estimate the direct, indirect and heterogeneous intention-to-treat (ITT) effects of the SSNP on migration, as outlined in our pre-analysis plan. 12

\subsubsection{Direct effects}

First we estimate the intent-to-treat (ITT) effects of the program by estimating the following regression equation:

$$
y_{i v}=\beta_{0}+\beta_{1} T_{i v}+\delta^{T} X_{i v}+\varepsilon_{i v}
$$

where $y_{i v}$ is the outcome of interest for household $i$ in village $v ; T_{i v}$ is a dummy indicating whether household $i$ in village $v$ was assigned to the treatment group or not; $X_{i v}$ is a vector of baseline covariates (included to improve precision); and $\varepsilon_{i v}$ is the disturbance term. The ITT effect of the program is measured by the coefficient $\beta_{1}$. We also estimate the local average treatment effects (LATE) by instrumenting the treatment status actually observed in the survey by the treatment assignment dummy $T_{i v}$.

\subsubsection{Indirect effects}

Indirect average treatment effects (ITE) of the SSNP are ascertained by comparing the outcomes of households in high intensity villages with those of households in low intensity villages. Specifically, we estimate an equation of the following form:

power issues and is mostly inconclusive. Results, available upon request, are not reported in this paper due to space limitation.

${ }^{12}$ Our pre-analysis plan is available here: http://egap.org/registration/5302. We specified that our plan was to analyze impacts in four main domains (labor market outcomes, economic outcomes, migration, non-material outcomes) and that we would present the results in different papers. Online Appendix C presents migration sub-analyses that were specified in the pre-analysis plan but are not incorporated in the paper due to space limitation. Results related to other domains are presented in Gazeaud et al. (2019). We discuss the problem of multiple hypothesis testing in Section 5.3 


$$
y_{i v}=\beta_{0}+\beta_{1} T_{i v}+\beta_{2} P_{40 v}+\beta_{3} T_{i v} * P_{40 v}+\delta^{T} X_{i v}+\varepsilon_{i v}
$$

where $y_{i v}$ is the outcome of interest for household $i$ in village $v ; T_{i v}$ is a dummy indicating whether household $i$ in village $v$ was assigned to the treatment group or not; $P_{40 v}$ is a dummy variable at the village level indicating an assignment rate of $40 \%$ in village $v ; T_{i v} * P_{40 v}$ is thus a dummy for being assigned to treatment in a village with an assignment rate of $40 \% ; X_{i v}$ is a vector of baseline covariates; and $\varepsilon_{i v}$ is the disturbance term.

The ITE on non-beneficiary households are estimated by the parameter $\beta_{2}$, that is the effect of being assigned to the control group in a village where $40 \%$ of the eligible population was assigned to treatment, compared to being assigned to the control group in a village where only $20 \%$ of the eligible population was assigned to treatment. The ITE on beneficiary households are given by $\beta_{2}+\beta_{3}$, that is the effect of being assigned to treatment in a village where $40 \%$ of the eligible population was assigned to treatment, compared to being assigned to treatment in a village where only $20 \%$ of the eligible population was assigned to treatment. 13

\subsubsection{Heterogeneous effects}

Finally, we estimate heterogeneous treatment effects with an equation of the following form:

$$
\begin{gathered}
y_{i v}=\beta_{0}+\beta_{1} T_{i v}+\beta_{2} \text { CHARACTERISTIC } C_{i v}+ \\
\beta_{3} T_{i v} * \text { CHARACTERISTIC } i v+\delta^{T} X_{i v}+\varepsilon_{i v}
\end{gathered}
$$

where $y_{i v}$ is the outcome of interest for household $i$ in village $v ; T_{i v}$ is a dummy indicating whether household $i$ in village $v$ was assigned to the treatment group or

\footnotetext{
${ }^{13}$ The type of spillover effects we are able to capture through this strategy are local in the sense that they occur for households that reside in the same village. Recent work by Egger et al. (2019) suggests that general equilibrium effects from cash transfers may operate at a broader level. While similar effects are possible in our context, in practice they are expected to be much smaller because only 4 percent of the households in our study area were treated (against 16 percent in Egger et al.), and because transfers were much smaller (US\$320 max in our study against US\$1,000 in Egger et al.). Overall, this suggests that the demand shock in Egger et al. was about 13 times more important than in our study.
} 
not; CHARACTERISTIC ${ }_{i v}$ corresponds to the dimension of heterogeneity studied for household $i$ in village $v ; T_{i v} *$ CHARACTERISTIC $i v$ is their interaction; $X_{i v}$ is a vector of baseline covariates; and $\varepsilon_{i v}$ is the disturbance term. This equation tests whether the effect of the program is conditional on baseline characteristics. Because baseline characteristics were not randomly allocated across households, the analysis of heterogeneous treatment effects should be considered as exploratory and results should not be interpreted as causal. In order to limit omitted-variable concerns, the vector of control variables includes the interaction terms of the dimension studied with other baseline characteristics.

\subsection{Data}

From the 69 villages selected to receive the intervention, seven villages that had less than 30 households were excluded from the experimental design because the number of beneficiaries would have been too small for public works. In these small villages, $100 \%$ of the eligible households participated in public works. The final sample for the empirical analysis is composed of 62 villages, including 37 villages from Grande Comore, 16 villages from Anjouan and 9 villages from Moheli. In each village, we sampled 25 beneficiary households and 15 pre-selected but non-beneficiary households. All households within a given village and category had the same probability of being sampled.

A baseline survey was conducted after household randomization and before the launch of CFW activities. The baseline survey took place in two phases to mirror program implementation timeline: ${ }^{14}$ (i) from July to September 2016 in one third of the villages and (ii) from December 2016 to May 2017 in the remaining two thirds. A follow-up survey was conducted between July and September 2018, while treated households had received between US\$140 and US\$320. Household attrition was low (about 4 percent of the baseline sample) and balanced across treatment and control

\footnotetext{
${ }^{14}$ The sampling frame required the completion of the targeting process, which was implemented in two phases by the implementing agency due to capacity constraints.
} 
Table 1: Household characteristics at baseline

\begin{tabular}{|c|c|c|c|c|c|c|}
\hline & \multicolumn{2}{|c|}{ Control } & \multicolumn{2}{|c|}{ Treatment } & \multirow[b]{2}{*}{ Diff } & \multirow[b]{2}{*}{$\mathrm{p}$-value } \\
\hline & Mean & SD & Mean & SD & & \\
\hline Household size & 6.55 & 2.80 & 6.57 & 2.82 & -0.01 & 0.91 \\
\hline Consumption (PAE) & 7.17 & 1.02 & 7.14 & 0.97 & 0.03 & 0.55 \\
\hline Has a bank account & 0.28 & 0.45 & 0.27 & 0.45 & 0.01 & 0.64 \\
\hline $\begin{array}{l}\text { Has an income generating activity } \\
\text { (other than agriculture) }\end{array}$ & 0.48 & 0.50 & 0.45 & 0.50 & 0.03 & 0.17 \\
\hline Owns fields & 0.76 & 0.43 & 0.75 & 0.43 & 0.01 & 0.72 \\
\hline Livestock (tropical unit) & 0.49 & 0.93 & 0.52 & 0.99 & -0.03 & 0.48 \\
\hline Has electricity & 0.59 & 0.49 & 0.60 & 0.49 & -0.01 & 0.50 \\
\hline Has a private water access & 0.63 & 0.48 & 0.63 & 0.48 & 0.01 & 0.74 \\
\hline Head is male & 0.77 & 0.42 & 0.76 & 0.43 & 0.01 & 0.59 \\
\hline Head age & 48.66 & 16.03 & 48.34 & 15.20 & 0.32 & 0.63 \\
\hline \multicolumn{7}{|l|}{ Head education } \\
\hline Did not complete primary & 0.56 & 0.50 & 0.58 & 0.49 & -0.02 & 0.39 \\
\hline Primary & 0.22 & 0.41 & 0.19 & 0.39 & 0.03 & $0.06^{*}$ \\
\hline Secondary & 0.18 & 0.38 & 0.19 & 0.39 & -0.01 & 0.48 \\
\hline Tertiary & 0.04 & 0.20 & 0.04 & 0.20 & -0.00 & 0.83 \\
\hline Willingness to migrate to Mayotte & 0.21 & 0.41 & 0.23 & 0.42 & -0.02 & 0.31 \\
\hline Migration experience to Mayotte & 0.54 & 1.33 & 0.51 & 1.53 & 0.03 & 0.61 \\
\hline Migrant network in Mayotte & 0.13 & 0.34 & 0.14 & 0.35 & -0.01 & 0.49 \\
\hline \multicolumn{7}{|l|}{ Island of residence } \\
\hline Ngazidja & 0.58 & 0.49 & 0.58 & 0.49 & 0.00 & 0.84 \\
\hline Ndzuani & 0.27 & 0.44 & 0.28 & 0.45 & -0.01 & 0.58 \\
\hline Mwali & 0.15 & 0.36 & 0.15 & 0.35 & 0.01 & 0.67 \\
\hline Debts & $1.1 \mathrm{e}+05$ & $1.7 e+05$ & $1.1 \mathrm{e}+05$ & $1.8 \mathrm{e}+05$ & -2827.67 & 0.71 \\
\hline F-test joint orthogonality & & & & & & 0.81 \\
\hline Observations & 900 & 900 & 1372 & 1372 & 2272 & 2272 \\
\hline
\end{tabular}

Notes: This table reports subsample means with standard deviations. The last column reports the pvalue of a t-test of mean equality across subsamples. The F-test corresponds to a regression of the treatment on baseline characteristics using the same specification as in equation 1) (omnibus test). An inverse hyperbolic sine transformation has been applied to consumption and debts. PAE denotes per adult equivalent. Migration experience corresponds to the total number of attempts made by household members. Migration network is defined using a dummy equal to one if the household head has at least one child residing in Mayotte.

groups ${ }^{15}$ INSEED, the national institute of statistics, was responsible for data collection and worked under the supervision of the authors. Enumerators were not informed of the treatment status of households prior to the interviews, and could thus only infer this information from questions related to CFW activities in the last module. Follow-up survey data are complemented by administrative data on the number and timing of cash transfers.

We implemented a qualitative survey as a complement to the quantitative survey. Qualitative research is useful to study perceptions, norms, and narratives, which

\footnotetext{
${ }^{15}$ Attrition will be discussed in depth in Section 5.3
} 
are complex and difficult to quantify. About 90 semi-structured interviews were conducted by local research assistants under the supervision of the authors. The sample of the qualitative survey included a broad range of actors, including (i) participants and non-participants in project activities, (ii) government officials and local community leaders, and (iii) NGOs and local firms in charge of the execution of CFW activities.

Table 1 summarizes key baseline variables and tests for balance between treatment and control groups. Only one of the 20 variables tested appears imbalanced $(\mathrm{p}<0.10)$, but the difference is relatively small in size. More importantly, the omnibus test of joint orthogonality is not rejected ( $\mathrm{p}=0.81$ ). This suggests that the randomized assignment of households to treatment has been implemented correctly.

\section{Results}

\subsection{Program take-up}

In Table 2, we test whether households assigned to treatment were indeed more likely to perform CFW activities and whether an improvement of their levels of employment and income is observed. On the one hand, access to CFW opportunities should directly increase employment and income levels of beneficiaries. On the other hand, substitution effects could undermine these direct effects, for example if beneficiaries gave up other profitable activities because of the labor requirement of the program. Our main outcome variables aggregate individual measures of employment and incomes at the household level.

In column 1 and 4 , we see that the randomization was effective at driving treated households to participate in CFW activities. Households randomly assigned to treatment worked significantly more days in public works during the 30 days preceding the follow-up survey than control households $(\mathrm{p}<0.001)$. However, some evidence of substitution effects can be seen from column 5. Treated households earned a lower total income than their control counterparts if cash-for-work income is excluded. This substitution effect is only visible for income, and is not sufficient to remove CFW pos- 
Table 2: Treatment effects on labor market outcomes

\begin{tabular}{|c|c|c|c|c|c|c|}
\hline & \multicolumn{3}{|c|}{ Employment } & \multicolumn{3}{|c|}{ Income } \\
\hline & $(1)$ & (2) & (3) & $(4)$ & (5) & (6) \\
\hline & CFW & $\begin{array}{c}\text { Total } \\
(\text { excl. CFW) }\end{array}$ & $\begin{array}{c}\text { Total } \\
\text { (incl. CFW) }\end{array}$ & CFW & $\begin{array}{c}\text { Total } \\
(\text { excl. CFW) }\end{array}$ & $\begin{array}{c}\text { Total } \\
\text { (incl. CFW) }\end{array}$ \\
\hline \multicolumn{7}{|l|}{ Panel A } \\
\hline Treatment & $\begin{array}{c}4.990^{* * *} \\
(0.317)\end{array}$ & $\begin{array}{c}0.409 \\
(1.617)\end{array}$ & $\begin{array}{c}5.399 * * * \\
(1.664)\end{array}$ & $\begin{array}{l}1.284^{* * *} \\
(0.074)\end{array}$ & $\begin{array}{c}-0.261^{* *} \\
(0.115)\end{array}$ & $\begin{array}{c}1.023^{* * *} \\
(0.138)\end{array}$ \\
\hline Extended controls & No & No & No & No & No & No \\
\hline Island FE & No & No & No & No & No & No \\
\hline \multicolumn{7}{|l|}{ Panel B } \\
\hline Treatment & $\begin{array}{c}4.898^{* * *} \\
(0.315)\end{array}$ & $\begin{array}{c}0.429 \\
(1.542)\end{array}$ & $\begin{array}{c}5.327^{* * *} \\
(1.587)\end{array}$ & $\begin{array}{l}1.264^{* * *} \\
(0.074)\end{array}$ & $\begin{array}{c}-0.240^{* *} \\
(0.109)\end{array}$ & $\begin{array}{c}1.024^{* * *} \\
(0.131)\end{array}$ \\
\hline Extended controls & Yes & Yes & Yes & Yes & Yes & Yes \\
\hline Island FE & No & No & No & No & No & No \\
\hline \multicolumn{7}{|l|}{ Panel C } \\
\hline Treatment & $\begin{array}{l}4.920^{* * *} \\
(0.313)\end{array}$ & $\begin{array}{c}0.371 \\
(1.511)\end{array}$ & $\begin{array}{l}5.291^{* * *} \\
(1.556)\end{array}$ & $\begin{array}{l}1.270^{* * *} \\
(0.073)\end{array}$ & $\begin{array}{c}-0.240^{* *} \\
(0.107)\end{array}$ & $\begin{array}{c}1.030^{* * *} \\
(0.129)\end{array}$ \\
\hline Extended controls & Yes & Yes & Yes & Yes & Yes & Yes \\
\hline Island FE & Yes & Yes & Yes & Yes & Yes & Yes \\
\hline Control mean & 1.881 & 51.924 & 53.805 & 0.489 & 3.098 & 3.587 \\
\hline Observations & 2181 & 2181 & 2181 & 2181 & 2181 & 2181 \\
\hline
\end{tabular}

Notes: This table shows estimates of equation (1) using data from the follow-up survey (30 days recall period) and various employment and income variables as outcome variables (aggregated at the household level). Employment variables are expressed as number of days worked (columns 1-3). CFW employment (column 1) corresponds to the number of days worked in CFW activities. Total employment, in columns 2 and 3, includes farming, livestock rearing, fishing, and other activities (and CFW if specified in the column header). An inverse hyperbolic sine (IHS) transformation has been applied to all income variables (columns 4-6). Robust standard errors are in parentheses. ${ }^{* * *}$ $\mathrm{p}<0.01,{ }^{* *} \mathrm{p}<0.05,{ }^{*} \mathrm{p}<0.1$.

itive direct effects. Overall, the total treatment effects on employment and income are substantial and positive (columns 3 and 6), such that the program can be considered as a large positive income shock. The estimates are similar when extended controls and island fixed effects are included in the specification (panels B and C).

The control group appears to have been slightly contaminated by the treatment. Control households reported an average of 1.88 days spent in public works during the month preceeding the survey. We further explore program take-up by looking at the treatment status reported by endline respondents themselves ${ }_{16}^{16}$ We find a noncompliance rate of $19.6 \%$ overall $(14.7 \%$ in the treatment group; $27.2 \%$ in the control group). The main explanation for non-compliance is related to the replacements of drop-out beneficiaries. For example, a respondent from the qualitative survey re-

\footnotetext{
${ }^{16}$ Questions on the program were asked in the last module of the survey in order to avoid influencing the behaviors of respondents and interviewers in other modules.
} 
ported that "after a month, I received the 20,000 KMF [US\$46] and decided to go back to my own farming because it was more profitable. My wife also didn't want to go to the public works. Then, another person took our place. I saw that the program was not going to help me much".

\subsection{Impact on migration}

The main results of the paper are presented in Table 3, where we report the ITT effect of the SSNP on migration to Mayotte. When preparing the survey, we were concerned about the sensitivity of the topic because migration of Comorians to Mayotte is usually illegal, especially for the study population which is poorer than the average Comorian and has a tiny probability of getting visas. In addition, many people have died in the last few decades trying to reach Mayotte and development agencies are increasingly concerned by the phenomenon. In terms of identification, experimenter demand effects and socially desirable answers could induce beneficiary households to be more reluctant to reveal migration to Mayotte, and this in turn would lead to lowerbound estimates. In order to avoid respondents discomfort and biased responses, we collected information as indirectly as possible, by leveraging data on household composition collected at baseline. In particular, our main measure of migration relies on questions asking whether each baseline household member is still residing in the household at follow-up, and if not, where he or she is currently residing with Mayotte as one of the choices. Because it does not make salient that the purpose of the questions is to assess migration to Mayotte, we believe that this design limits the risks of respondents' discomfort and reporting bias.

Because the French police expels a large number of illegal Comorians every year, migration is often short-term $\sqrt[17]{17}$ Therefore, we also collected information on return migrants, by inquiring whether any household member at follow-up took a kwassa for Mayotte in the last 24 months. This measure is not without caveats and could bias the

\footnotetext{
${ }^{17}$ Each year, about 20,000 migrants are deported to Comoros (Sénat, 2008). This corresponds to roughly 8 percent of Mayotte population or 2.5 percent of Comoros population.
} 
Table 3: Treatment effects on migration to Mayotte

\begin{tabular}{lccccccc}
\hline \hline & \multicolumn{3}{c}{$\begin{array}{c}\text { Migration } \\
\text { (excl. returns) }\end{array}$} & & \multicolumn{3}{c}{$\begin{array}{c}\text { Migration } \\
\text { (incl. returns) }\end{array}$} \\
\cline { 2 - 4 } \cline { 7 - 9 } & $(1)$ & $(2)$ & $(3)$ & & $(4)$ & $(5)$ & $(6)$ \\
\hline Treatment & $0.030^{* *}$ & $0.028^{* *}$ & $0.028^{* *}$ & & $0.036^{* *}$ & $0.034^{* *}$ & $0.034^{* *}$ \\
& $(0.013)$ & $(0.012)$ & $(0.012)$ & & $(0.015)$ & $(0.015)$ & $(0.015)$ \\
\hline Extended controls & No & Yes & Yes & & No & Yes & Yes \\
Island FE & No & No & Yes & & No & No & Yes \\
Control mean & 0.078 & 0.078 & 0.078 & & 0.128 & 0.128 & 0.128 \\
Observations & 2181 & 2181 & 2181 & & 2181 & 2181 & 2181 \\
\hline
\end{tabular}

Notes: This table reports LPM estimates of treatment effects on migration using equation (1). The dependent variable in columns 1 to 3 is a dummy equal to one if at least one household member migrated to Mayotte after the baseline survey and is still in Mayotte during the follow-up survey. In columns 4 to 6, the dependent variable also equals one if at least one household member migrated to Mayotte after the baseline survey but returned to his household of origin (voluntarily or not). Extended controls include the following variables (measured at baseline): household willingness to migrate; migration experience; network in Mayotte; household head's gender, age, and schooling; household size, consumption, and livestock; dummy variables equal to one if the household has a bank account, income-generation activities (other than agriculture), fields, electricity, and a private water access. Robust standard errors are in parentheses. ${ }^{* * *} \mathrm{p}<0.01,{ }^{* *} \mathrm{p}<0.05,{ }^{*} \mathrm{p}<0.1$.

estimates, given that (i) it is more direct and thus exposed to the reporting bias mentioned above, (ii) the 24 months recall period may include pre-program migrations because of program's progressive roll-out, and (iii) it does not inquire about household members who have died (some of which may have died en route to Mayotte), or household members who have left the household and are not currently in Mayotte, but could still have been in Mayotte in between. ${ }^{18}$ These caveats are likely to attenuate our estimates of treatment effects.

We find that the program had a sizable and positive impact on migration to Mayotte. Column 1 shows that the treatment increased migration to Mayotte by three percentage points (significant at the 5\% level), which represents a 38 percent increase relative to the control group. Results are robust to the inclusion of returnees. Estimates of treatment effects are larger in absolute terms but smaller in relative terms (consistent with the attenuation bias highlighted above). As can be seen in column 4, the program increased migration by 3.6 percentage points, equivalent to a 28 percent

\footnotetext{
${ }^{18}$ Comorian migrants are always deported to Anjouan (Mayotte's closest neighbor), even though they are from Grande Comore or Moheli. Then, they either return to their island of origin, settle in a new location, or try to get back to Mayotte.
} 
increase relative to the control group. Results are stable when extended controls and island fixed effects are included (columns 2, 3, 5 and 6).

Table A2 shows that LATE estimates are about 5.1 percentage points without the returnees and 6.3 percentage points with them. Not surprisingly, LATE estimates are consistently larger than ITT estimates suggesting that the program increased migration within the sample of compliers.

We use an IV strategy to estimate the average income elasticity of migration for poor households in Comoros (Table A3). In the first-stage regression, we regress the logarithm of household income - including cash-for-work transfers - on the treatment dummy ${ }^{19}$ The instrument is strong, with Kleibergen-Paap Wald F-statistics ranging between 19.8 without control variables and 37.2 with control variables and island fixed effects. Household incomes in the treatment group are on average about $36 \%$ higher than in the control group.20 In the second-stage regression, we study how the exogenous income shock resulting from the cash-for-work program affects migration. Results suggest that a $1 \%$ increase in income increases migration by 0.08 percentage points. This corresponds to an income elasticity of migration of about 1.21 This estimate is very close to Bazzi (2017)'s estimates of the income elasticity of international migration from Indonesia - around 1 for permanent agricultural income shocks and around 0.1 for transitory shocks. Using data from Angelucci (2015), Bazzi (2017) estimated that the income elasticity of Mexico-US migration is around 2.3.22

\footnotetext{
${ }^{19}$ The measure of household income is the sum of the monthly income at baseline and, for households who participated in the cash-for-work program, the monthly average value of transfers received. We exclude from this analysis the $11 \%$ of households that do not report income at baseline, as the concept of elasticity does not make sense in zero (Delius and Sterck. 2020).

${ }^{20}$ We use the formula $\exp (\beta)-1$ to approximate the semi-elasticity.

${ }^{21}$ The average income elasticity of migration is obtained by dividing the regression coefficient by the average migration rate in the control group. For at least three reasons, our estimate of the income elasticity of migration should be interpreted with caution. First, because of the IV strategy, confidence intervals around regression coefficients are relatively large. Second, the measure of income is constructed using baseline survey data and administrative data on cash transfers; it is therefore expected to be a good but imperfect proxy for the total income that households earned during the duration of the cash-for-work program. Finally, this analysis was not pre-specified in our pre-analysis plan and should therefore be considered as exploratory.

${ }^{22}$ Note that we can unfortunately not exploit the uneven roll-out of the CFW program to assess the income elasticity of migration at various income levels because the uneven roll-out of the program is not exogenous. Having received more CFW rounds is associated with lower levels of consumption and income and higher willingness to migrate at baseline ( $p$-values $<0.01)$.
} 
In Table A4, we explore the profitability of migration to Mayotte by looking at the impact of the program on remittances. Remittances are measured using two main variables: (i) a dummy indicating whether the migrant sent remittances to his or her household of origin (using a 12 months recall period); (ii) the total amount of remittances sent. While the results suggest that the program had a positive effect on remittances, coefficients are small in absolute terms and only marginally significant (pvalues range between 0.08 and 0.18 ). The latter could be explained by the fact that our study is not powered to study such second-order effects. We also note that migration could take time to become profitable, especially in a setting where migration is typically irregular and migrants face important risks of deportation. This point is illustrated in Figure A2, which identifies a positive correlation between migration duration and migrants' likelihood of spending remittances in the 12 months prior to the follow-up survey (using the full sample of household migrants, i.e. also including individuals who have migrated to Mayotte before the baseline survey).

\subsection{Threats to our interpretation}

These results are consistent with the idea that the cash-for-work program increased migration to Mayotte. However, this interpretation is exposed to various threats that could produce a similar pattern in the data. We explore four alternative explanations for the observed effects: (i) selective attrition; (ii) selective household dissolution; (iii) negative indirect effects on control households, and (iv) multiple hypothesis testing.

Selective attrition Because attrition can sometimes be explained by whole household migration, a typical concern with impact evaluation looking at migration is related to differential attrition rates between experimental groups. In our case study, estimates would be biased upwards if households in the control group were more affected by whole household migration than households in the treatment group. This concern appears to be irrelevant in our study. First, the attrition rate is very low (about $4 \%$ ) and similar across experimental groups (Table A5. Moreover, qualitative inter- 
views indicate that whole household migration to Mayotte is uncommon. Households typically send one migrant, two at most (when a parent migrates with his or her child). As a respondent put it: "I do not know of any family that has migrated entirely to Mayotte. Most often, there is only one person who migrates because that is enough to help others." Many respondents also mentioned the high migration costs and risks to explain that whole household migration is unusual. Finally, even if we considered an unlikely scenario in which all attritors migrated to Mayotte, we would still observe a positive impact on migration.

Selective household dissolution A similar concern is related to household dissolution and migration. As shown by Bertoli and Murard (2019), the migration of an individual increases the probability that his or her household of origin dissolves subsequently. Because the program was targeted at the household level, beneficiary households may have had an incentive to preserve their living arrangements after the migration of a household member, thus being relatively less likely to dissolve. Again, this would lead to a relatively higher attrition rate in the control group and would bias our results upwards. In Table A6, we check whether beneficiary households are less likely to dissolve by analyzing attrition reasons given by enumerators. Reassuringly, household dissolution was similar in the control and treatment groups. About two percent of households in both experimental groups could not be followed-up because they dissolved 23

Negative indirect effects on control households A number of recent studies highlight the importance to estimate not just direct effects of anti-poverty programs but also their indirect effects (Angelucci and De Giorgi, 2009; Beegle et al., 2017). In our

\footnotetext{
${ }^{23}$ Two ingredients of the project implementation may explain this pattern. First, payments were made to individuals performing the work rather than to household heads. Second, formal and informal arrangements to replace workers were possible both within and across households. Drop-out workers were supposed to be replaced by another household member, but in practice, the implementing agency did not keep track of the exact initial household composition, meaning that the choice of the replacement could incorporate household changes. The qualitative interviews with beneficiaries reveal that replacements by extended family members or relatives were quite common. Taken together, these observations support the idea that incentives for beneficiaries to preserve the household structure were likely weak in practice.
} 
case study, control households could benefit indirectly from the program, for example through solidarity or redistribution norms. The program could also ease the credit constraints of control households if beneficiaries lend part of their transfers to control households. Such indirect effects could increase migration rates in the control group as well. Positive spillovers on migration were observed by Akram et al. (2017) following a program of transport subsidies in Bangladesh. Negative spillovers are also possible, as control households could for example be hurt by price spikes or increased competition for scarce investment opportunities. ${ }^{24}$ We estimate indirect effects using equation (2). Table A7 reports the sign and magnitude of indirect effects on both experimental groups. We see no evidence of significant indirect treatment effects. Our estimates suggest these effects are small and similar across treatment and control groups. However, confidence intervals are quite large, implying that we cannot rule out spillovers that are economically meaningful.

Multiple hypothesis testing In our pre-analysis plan, we committed to assess the impact of the program on 12 main outcomes of interest, which were categorized in four families: labor market outcomes, economic outcomes, migration, and non-material outcomes. The present paper focuses on labor market outcomes and migration. ${ }^{25}$ This raises the question of whether inferences are robust to corrections for multiple hypothesis testing. We estimate sharpened q-values that control the false discovery rate (FDR) following the two-step procedure described by Benjamini et al. (2006) and Anderson (2008) ${ }^{26}$ Without correction for multiple hypothesis testing, the p-value of the treatment effect on migration is 0.019 . We were expecting little effect on the four non-material outcomes listed in the pre-analysis plan. The sharpened q-value of the treatment dummy is 0.040 when considering only the 8 outcomes for which we were expecting a significant impact (table A8 in appendix). The sharpened q-value is 0.068

\footnotetext{
${ }^{24}$ Control households could also believe that they will receive the program in the future, and delay their migration if they stop saving.

${ }^{25}$ As explained in the pre-analysis plan, other outcomes will be analyzed in separate paper.

${ }^{26}$ In our pre-analysis plan, we committed to implement corrections for multiple hypothesis testing within each family of outcomes but not across. We thank an anonymous referee for encouraging us to adopt a more prudent approach and implement the corrections for all outcomes of interest.
} 
when considering all 12 outcomes. The p-values and q-values associated with labor market outcomes are all below 0.01. Overall, these results suggest that our inferences are robust to corrections for multiple hypothesis testing.

\section{Channels}

Various channels may explain why the cash-for-work program increased migration to Mayotte. We explore the four channels highlighted in the theory section: (i) the liquidity channel; (ii) the opportunity cost channel; (iii) the collateral channel; and (iv) the risk-aversion channel ${ }^{27}$ Identifying which channels of impact are active and why they are active (or not) is important, first to understand whether findings are likely to generalize to other contexts and other programs, and second to understand the policy implications of the research. This section should be regarded as exploratory since it was not included in our pre-analysis plan and since it exploits non-experimental variation in the data. We find suggestive evidence that the increase in migration is driven by the alleviation of liquidity and risk constraints on one hand, and by the fact that the program did not increase the opportunity cost of the individuals who were the most likely to migrate on the other hand.

\subsection{Liquidity channel}

According to the liquidity channel, cash transfers relax the budget constraint of households, thus facilitating the migration of those unable to finance migration without the transfers. In order to check whether this channel is relevant in our setting, we estimate program effects conditional on baseline savings using equation (3). 28 In line with the liquidity channel, positive effects on migration are concentrated within the group of

\footnotetext{
${ }^{27}$ In this section, we focus on our first definition of migration (i.e. excluding return migrants) due to space limitation. Results including return migrants are similar (available upon request).

${ }^{28}$ It is often challenging to measure savings, especially in low-income settings where it can take various forms. In Comoros, households typically save using livestock and tontines. In addition, many households take on debts from various operators (friends, shop owners, etc.) such that their savings can actually be negative. In order to capture household net savings, we derive a variable combining the value stored in these various vehicles. Specifically, the money saved in livestock and tontines enter positively in the variable, whereas the amount of debts enter negatively.
} 
households with low baseline savings (Table 4). In addition, the migration rate in the control group was relatively higher for households with high baseline savings, suggesting that financial constraints are binding in our setting. Overall, it seems that cash transfers allowed some households with low levels of savings at baseline to overcome otherwise binding financial constraints ${ }^{29}$ Results are qualitatively unchanged when using a continuous variable for savings.

Table 4: Liquidity channel

\begin{tabular}{|c|c|c|c|c|c|c|}
\hline & \multicolumn{6}{|c|}{ Migration (excl. returns) } \\
\hline & \multicolumn{3}{|c|}{ Savings $=$ dummy } & \multicolumn{3}{|c|}{ Savings $=$ continuous } \\
\hline & $(1)$ & $(2)$ & (3) & $(4)$ & $(5)$ & (6) \\
\hline \multirow[t]{2}{*}{ Treatment $\left(\beta_{1}\right)$} & $0.062^{* * *}$ & $0.064^{* * *}$ & $0.064^{* * *}$ & $0.039^{* * *}$ & $0.040^{* * *}$ & $0.039^{* * *}$ \\
\hline & $(0.020)$ & $(0.020)$ & $(0.020)$ & $(0.013)$ & $(0.013)$ & $(0.013)$ \\
\hline \multirow[t]{2}{*}{ Savings } & 0.024 & 0.027 & 0.030 & 0.001 & 0.001 & 0.001 \\
\hline & $(0.019)$ & $(0.019)$ & $(0.163)$ & $(0.001)$ & $(0.001)$ & $(0.007)$ \\
\hline \multirow[t]{2}{*}{ Treatment $\times$ Savings $\left(\beta_{3}\right)$} & $-0.051^{* *}$ & $-0.054^{* *}$ & $-0.056^{* *}$ & $-0.002^{*}$ & $-0.002^{*}$ & $-0.002^{*}$ \\
\hline & $(0.025)$ & $(0.025)$ & $(0.025)$ & $(0.001)$ & $(0.001)$ & $(0.001)$ \\
\hline \multirow[t]{2}{*}{$\beta_{1}+\beta_{3}$} & 0.011 & 0.010 & 0.008 & & & \\
\hline & $(0.015)$ & $(0.015)$ & $(0.015)$ & & & \\
\hline Control mean (low savings) & 0.064 & 0.064 & 0.064 & 0.064 & 0.064 & 0.064 \\
\hline Extended controls & $\checkmark$ & $\checkmark$ & $\checkmark$ & $\checkmark$ & $\checkmark$ & $\checkmark$ \\
\hline Island FE & & $\checkmark$ & $\checkmark$ & & $\checkmark$ & $\checkmark$ \\
\hline Savings $\times$ Controls & & & $\checkmark$ & & & $\checkmark$ \\
\hline Observations & 2181 & 2181 & 2181 & 2181 & 2181 & 2181 \\
\hline
\end{tabular}

Notes: This table reports estimates of treatment effects conditional on savings using equation 3]. In columns 1 to 3 , households are divided in two groups depending on their baseline savings (below or above the mean). In columns 4 to 6 , baseline savings are introduced as a continuous variable. An IHS transformation was applied in order to limit the influence of outliers. See notes to Table 3 for other details. Robust standard errors are in parentheses. *** $\mathrm{p}<0.01,{ }^{* *} \mathrm{p}<0.05,{ }^{*} \mathrm{p}<0.1$.

Our second approach to investigate the liquidity channel is to look at program effects on migration to other destinations. If the increase in migration to Mayotte is due to relaxed financial constraints, we should not detect similar effects on migration to cheaper, previously unconstrained destinations. As can be seen from Table A9, the program had small and non-significant effects on domestic migration. We do not ob-

\footnotetext{
${ }^{29}$ Figure A3 shows the results graphically. Figure A4 tests for the presence of a non-linear relationship by splitting the sample into three groups according to their baseline level of savings. According to the theoretical model in online appendix $B$, the treatment effect can be a non-linear function of baseline savings. If upfront migration cost is large, such that $c-w_{0}-\tau$, only households with intermediate levels of savings will react to the treatment. In our context, however, the condition $c-w_{o}-\tau$ is unlikely to be satisfied as the value of the cash transfer was broadly equivalent to the cost of migrating to Mayotte. In our experiment, we therefore expect that the treatment effect is a decreasing function of baseline savings.
} 
serve effects on migration to mainland France either, most likely because the binding constraint for this destination is administrative rather than financial.

\subsection{Opportunity cost channel}

As shown in Appendix B.2, cash transfers that are conditional on remaining in the origin country increase the opportunity cost of migrating and could therefore reduce migration. According to the opportunity cost channel, the impact of cash transfers on migration should therefore be negative, which is not what we observe in our experiment. We argue that the opportunity cost channel has not been operating in our setting because the cash-for-work program was very flexible. Beneficiary households were entitled to send one adult of their choice to public works and, most importantly, the cash transfers were not conditional upon other household members staying in Comoros. Beneficiary households could therefore select one household member to participate in public works activities, and, in the meantime, use the cash transfers to finance the migration of another household member. This conjecture is reinforced by qualitative evidence, which suggests that people are financing the migration of others: "I gave 40,000 KMF [US\$92] to my son for his trip to Mayotte. Life is hard. We had no one to ask for help. My son decided alone to leave in the hope of helping us. I didn't have much. But to encourage him, I gave this small amount".

Although in theory the cash-for-work program could have still increased the opportunity cost of migrating for the participants in CFW activities, in practice CFW workers were very different from the average migrant. As can be seen in Table A10. workers were on average older and less educated than migrants, and most workers were females with no migration experience while a majority of migrants were males. This suggests that the program primarily increased the opportunity cost of individuals who were unlikely to migrate (i.e. relatively old and poorly educated females with no previous migration experience). Table A10 may actually suggest that participation in CFW activities did not deter migration at all, since treated and control migrants are very similar (column 10). In Table A14, we also check whether the treatment effect on 
migration varies depending on the number of adults per household at baseline, and find no evidence of heterogeneous effects. The coefficient of the interaction term between the treatment dummy and the number of working age adults is very close to zero and not statistically significant (column 3) 30

\subsection{Collateral channel}

According to the collateral channel, future cash transfers can be used as a collateral by credit-constrained households to facilitate access to credit and finance migration upon their selection into the cash-transfer program. Our evidence suggests that the collateral channel is negligible in this study. First, control and treated households had similar baseline levels of debts (Table 1), suggesting that beneficiary households had not yet altered their financial behaviors at the time of the baseline survey although they already knew they would benefit from the cash transfers. Similarly, at followup, we see no significant differences between treated and control households in terms of debt levels (Table A11). Second, in Table 5 we explore the effect of the program on migration by means of financing. Households in our sample typically rely on three methods to finance migration: savings, debts, and help of relatives. During the survey, households with migrants were asked how migration was financed. The results suggest that migration episodes induced by the treatment were financed through savings or transfers from relatives, but not through credit.

Finally, when respondents reported a migrant, we further inquired about the month and year of migration. This retrospective data allows us to explore the evolution of the treatment effect over time ${ }^{31}$ We assemble a panel with detailed information about the history of migration and cash transfers. We are particularly interested to check (i)

\footnotetext{
${ }^{30}$ While this result could suggest a lack of relevance of the opportunity cost channel, we note that the mediating effect of the number of working age adults is theoretically ambiguous. The more workingage adults in the household, the less binding the labor requirement of CFW opportunities. However, the marginal effect of cash received may be smaller in larger households. Note that only $8.34 \%$ of households in our sample have one adult only.

${ }^{31} 25$ percent of the respondents only recalled the year of migration and are thus excluded from the pool of migrant households for this analysis. As a robustness check, we replaced missing months by randomly generated months. Results, available upon request, show that the dynamic of the treatment effect is the same though the estimates are more precise.
} 
Table 5: Treatment effects by means of financing

\begin{tabular}{lccc}
\hline \hline & \multicolumn{3}{c}{ Migration (excl. returns) } \\
\cline { 2 - 4 } & $(1)$ & $(2)$ & $(3)$ \\
& Savings & Debts & Help \\
\hline Treatment & $0.015^{* *}$ & 0.001 & $0.015^{*}$ \\
& $(0.007)$ & $(0.008)$ & $(0.008)$ \\
\hline Extended controls & Yes & Yes & Yes \\
Island FE & Yes & Yes & Yes \\
Control mean & 0.021 & 0.035 & 0.028 \\
Observations & 2163 & 2163 & 2163 \\
\hline
\end{tabular}

Notes: Outcome variables are dummies equal to one if at least one individual in the household migrated to Mayotte and if the household reported that the main source of funding to finance migration was savings (column 1), debt (column 2), or help from relatives (column 3); the dummies are equal to zero otherwise. Robust standard errors are in parentheses. ${ }^{* * *} \mathrm{p}<0.01,{ }^{* *} \mathrm{p}<0.05$, * $\mathrm{p}<0.1$.

whether migration decisions at time $t$ are explained by the amount of cash received at time $t$, the cash received at time $t-1$, or the total cash received pre- $t$, and (ii) whether the impact of the cash received at time $t$ is conditional on the total amount of cash received beforehand. In Table 6, we see that most of the impact seems to come from cash received at time $t$ (column 1), meaning that individuals reacted rather quickly to cash transfers. In contrast, cash transfers received at time $t$ - 1 did not seem to make much difference (column 2). However, it is interesting to see in column 3 that the impact of cash received at time $t$ is actually conditional on the total amount received beforehand. Overall, it seems that migration occurred in time periods where households received cash conditional on having accumulated enough liquidity in the previous periods ${ }^{32}$ If anything, this evidence reinforces the relevance of the liquidity channel (Section 6.1).

\subsection{Risk-aversion channel}

As shown in our simple theoretical model, if migration is risky and households have DARA preferences, cash transfers reduce risk-aversion and thereby increase the expected utility returns from migration. This risk-aversion channel is particularly relevant in our context, as Comorians migrating to Mayotte face considerable risks of death or expulsion. As emphasized in Section 3.1, thousands of Comorian migrants

\footnotetext{
${ }^{32}$ Figure A5 depicts these patterns in a more descriptive way.
} 
Table 6: Timing of cash transfers and migration

\begin{tabular}{|c|c|c|c|}
\hline & \multicolumn{3}{|c|}{ Migration $t$} \\
\hline & $(1)$ & $(2)$ & (3) \\
\hline Cash $\mathrm{t}$ & $\begin{array}{c}0.0044^{* * *} \\
(0.002)\end{array}$ & $\begin{array}{c}0.0049^{* * *} \\
(0.002)\end{array}$ & $\begin{array}{l}0.0002 \\
(0.002)\end{array}$ \\
\hline Cash Tot. t-1 & $\begin{array}{l}0.0006 \\
(0.000)\end{array}$ & & $\begin{array}{l}-0.0003 \\
(0.000)\end{array}$ \\
\hline Cash $\mathrm{t}-1$ & & $\begin{array}{c}-0.0032 \\
(0.002)\end{array}$ & \\
\hline Cash Tot. t-2 & & $\begin{array}{l}0.0014^{*} \\
(0.001)\end{array}$ & \\
\hline Cash $\mathrm{t}$ x Cash Tot. $\mathrm{t}-1$ & & & $\begin{array}{c}0.0028^{* * *} \\
(0.001)\end{array}$ \\
\hline Migration t-1 & $\begin{array}{c}0.982^{* * *} \\
(0.002)\end{array}$ & $\begin{array}{c}0.981^{* * *} \\
(0.003)\end{array}$ & $\begin{array}{c}0.982^{* * *} \\
(0.002)\end{array}$ \\
\hline Extended controls & Yes & Yes & Yes \\
\hline Island FE & Yes & Yes & Yes \\
\hline Control mean & 0.023 & 0.023 & 0.023 \\
\hline Observations & 17304 & 15141 & 17304 \\
\hline
\end{tabular}

have died in the attempt to reach Mayotte, and even more have been arrested and deported to Comoros. Qualitative interviews suggest that these risks have a strong influence on migration decisions, as illustrated in the following quote: "There are two things that automatically get inside the minds of the person who wants to migrate and his family: the risk of dying in the sea which is very common; the risk of being arrested by the police which can be really painful considering the expenses incurred". In addition, we believe that it is reasonable to assume DARA preferences in a setting suffering from widespread poverty and a lack of formal social safety nets. In this context, many households could face a "subsistence constraint", defined by Bryan et al. (2014) as a situation where poverty is so strong that failed investments would lead to unbearable welfare losses.

To investigate this channel, we estimate program effects conditional on a proxy measure of risk-aversion at baseline. Our measure of risk-aversion is derived from a simple discrete choice experiment conducted on the sub-sample of households willing to migrate by kwassa at baseline (21.8\% of the sample or 476 households). Respondents were asked to make a choice about the number of persons in the kwassa. Our qualitative evidence indicates that aspiring migrants typically face this choice in the real world and trade-off migration costs and migration risks. The more persons in a kwassa, the lower the price of the journey but the higher the risks of accident or arrest. 
Respondents were presented with three choices: (1) an overloaded kwassa (the less expensive but most risky technology); (2) a properly loaded kwassa; (3) what is often called a VIP kwassa, i.e. a kwassa with very few people (the most expensive but less risky technology). The exact question was as follows: 33

Imagine that you should take a small kwassa to migrate to Mayotte. The maximum capacity of the kwassa is 10 persons. You have the choice between three prices:

1. You pay 100,000 KMF [US\$230] and more than 10 persons on the kwassa

2. You pay 250,000 KMF [US\$575] and between 5 to 10 persons on the kwassa

3. You pay 500,000 KMF [US\$1150] and less than 5 persons on the kwassa

Which option would you choose?

Overall, $50.1 \%$ of the respondents selected choice (1), $20.6 \%$ choice (2), and $28.3 \%$ choice (3). We estimate a simple regression of the choice on baseline consumption and use the residuals as a proxy of risk-aversion. In other words, risk-aversion is derived from the part of the choice that is not explained by household wealth ${ }_{4}^{34}$ In line with the risk-aversion channel, positive effects of the program on migration are concentrated within the group of households with high levels of risk-aversion at baseline (Table 7) 35 In the control group, migration is lower among the highly risk-averse, which is consistent with DARA preferences and the theoretical result that risk aversion is a barrier to migration. The results are qualitatively unchanged when using a continuous variable for risk-aversion (although less statistically significant).

\footnotetext{
${ }^{33}$ These choices have been calibrated during enumerators' training and the pilot survey to reflect real world choices in as much as possible.

${ }^{34}$ In line with our expectations, we find that choosing a less risky option is strongly and positively associated with baseline consumption levels ( $p<0.001$; results available upon request).

${ }^{35}$ Figure A3 shows the results graphically. According to the theoretical model, the heterogeneous treatment effect with risk-aversion could be non-linear. Highly risk-averse households do not migrate in $t_{2}$ even with the cash transfers. Households with intermediate levels of risk-aversion do not migrate in $t_{1}$ but migrate in $t_{2}$ if they receive the cash transfers. Households with low level of risk-aversion migrate in $t_{1}$ and hence do not respond to the treatment. In Figure A7, we test for the presence of such non-linear heterogeneous treatment effect by splitting the sample into three groups according to their baseline level of risk aversion. Results are qualitatively similar, suggesting that the heterogeneous treatment effect with risk-aversion is mostly linear in our context.
} 
Table 7: Risk-aversion channel

\begin{tabular}{|c|c|c|c|c|c|c|}
\hline & \multicolumn{6}{|c|}{ Migration (excluding returns) } \\
\hline & \multicolumn{3}{|c|}{ Risk-aversion $=$ dummy } & \multicolumn{3}{|c|}{ Risk-aversion $=$ continuous } \\
\hline & $(1)$ & $(2)$ & (3) & $(4)$ & $(5)$ & $(6)$ \\
\hline \multirow[t]{2}{*}{ Treatment $\left(\beta_{1}\right)$} & 0.002 & 0.004 & 0.000 & 0.049 & 0.049 & 0.041 \\
\hline & $(0.042)$ & $(0.042)$ & $(0.042)$ & $(0.031)$ & $(0.030)$ & $(0.033)$ \\
\hline \multirow[t]{2}{*}{ Risk aversion } & $-0.086^{*}$ & $-0.083^{*}$ & -0.518 & -0.035 & -0.035 & -0.550 \\
\hline & $(0.046)$ & $(0.047)$ & $(0.386)$ & $(0.026)$ & $(0.026)$ & $(0.657)$ \\
\hline \multirow[t]{2}{*}{ Treatment $\times$ Risk aversion $\left(\beta_{3}\right)$} & $0.104^{*}$ & 0.101 & $0.106^{*}$ & 0.036 & 0.036 & 0.033 \\
\hline & $(0.063)$ & $(0.063)$ & $(0.063)$ & $(0.036)$ & $(0.036)$ & $(0.036)$ \\
\hline \multirow[t]{2}{*}{$\beta_{1}+\beta_{3}$} & $0.107^{* *}$ & $0.105^{* *}$ & $0.106^{* *}$ & & & \\
\hline & $(0.046)$ & $(0.046)$ & $(0.046)$ & & & \\
\hline Control mean (low risk-aversion) & 0.134 & 0.134 & 0.134 & 0.134 & 0.134 & 0.134 \\
\hline Extended controls & $\checkmark$ & $\checkmark$ & $\checkmark$ & $\checkmark$ & $\checkmark$ & $\checkmark$ \\
\hline Island FE & & $\checkmark$ & $\checkmark$ & & $\checkmark$ & $\checkmark$ \\
\hline Risk-aversion $\times$ Controls & & & $\checkmark$ & & & $\checkmark$ \\
\hline Observations & 476 & 476 & 476 & 476 & 476 & 476 \\
\hline
\end{tabular}

Notes: This table reports estimates of treatment effects conditional on risk-aversion using equation (3). In columns 1 to 3 , households are divided in two groups depending on their baseline levels (below or above the mean). In columns 4 to 6 , baseline risk-aversion is introduced as a continuous variable. See notes to Table 3 for other details. Robust standard errors are in parentheses. ${ }^{* *} \mathrm{p}<0.01,{ }^{* *} \mathrm{p}<0.05,{ }^{*} \mathrm{p}<0.1$.

\section{Conclusion}

Although international migration can lead to large income gains (McKenzie et al., 2010; Clemens, 2011; Gibson and McKenzie, 2012), existing migration flows remain relatively limited compared to the 750 million aspiring migrants (Esipova et al., 2018). The low realization rates are partly explained by policy barriers (Clemens, 2011), by binding liquidity and credit constraints (Angelucci, 2015; Bazzi, 2017; Cai, 2018), and by the high perceived risks of migration (Bah and Batista, 2018). The growing number of cash transfer programs in low- and middle-income countries could relax some of these constraints and further fuel international migration. Yet, empirical evidence on the link between cash transfers and international migration is limited (Adhikari and Gentilini, 2018).

In this paper, we showed that cash transfers targeted to very poor households in Comoros increased migration to the neighboring and richer French island of Mayotte. The increase in migration seems to be explained by the alleviation of liquidity and risk constraints on one hand, and by the fact that the program did not increase the opportunity cost of the persons who were the most likely to migrate on the other hand. These 
findings confirm that many households do not migrate because of binding financial constraints (Angelucci, 2015; Bazzi, 2017). It also contributes to the nascent literature showing that risk is an important deterrent in the decision to migrate (see e.g. Bryan et al. 2014; Kleemans 2015; Dustmann et al. 2017; Shrestha 2019a). While our findings confirm that risk is an important barrier to migration, they also suggest that a social protection program such as the SSNP can ease risk aversion and thereby increase risky migrations.

Recognizing the diversity of policy preferences over migration and the sensitivity of the topic, we refrain from proposing policy recommendations. Instead, we conclude by discussing several questions that were beyond the scope of this paper due to lack of data or insufficient statistical power, but that are nonetheless essential to better understand the relationship between cash-based programming and migration. We highlight three fruitful areas of future research. First, it would be useful to document the welfare consequences for households investing in migration. Bryan et al. (2014) and Meghir et al. (2019) investigate this question through a program that provides small transport subsidies to potential seasonal migrants in Bangladesh. Our study is not powered to explore this important question. Second, our research focuses on short-run effects. In the medium or long run, effects could be larger, as more households from the treatment group accumulate enough savings to finance migration (the program was still ongoing at the time of our endline survey). But another possibility is that, in the long run, all households - even in the control group - will have eventually accumulated enough savings to finance migration, in which case all the program does is bring forward migration. In this latter case, the long-run effect of the program would be null. More research is needed to identify how the effects of cash transfer programs on migration evolve over time. Finally, future empirical studies should focus on better understanding possible differential migration decisions by individuals and households. Our study assumed that migration choices are similar for the household as a unit and for individual members. Yet, empirical studies such as Dustmann et al. (2017) have shown that the relation between individual preferences and households' 
migration decisions are complex. Future research should investigate how individual preferences interact with cash-for-work programs to influence migration decisions.

\section{References}

Abadie, A., Chingos, M. M., and West, M. R. (2018). Endogenous stratification in randomized experiments. Review of Economics and Statistics, 100(4):567-580.

Adhikari, S. and Gentilini, U. (2018). Should I stay or should I go: Do cash transfers affect migration? Technical report, The World Bank.

Akgüç, M., Liu, X., Tani, M., and Zimmermann, K. F. (2016). Risk attitudes and migration. China Economic Review, 37:166-176.

Akram, A. A., Chowdhury, S., and Mobarak, A. M. (2017). Effects of emigration on rural labor markets. Technical report, National Bureau of Economic Research.

Anderson, M. L. (2008). Multiple inference and gender differences in the effects of early intervention: A reevaluation of the Abecedarian, Perry Preschool, and Early Training Projects. Journal of the American Statistical Association, 103(484):1481-1495.

Angelucci, M. (2015). Migration and financial constraints: Evidence from Mexico. Review of Economics and Statistics, 97(1):224-228.

Angelucci, M. and De Giorgi, G. (2009). Indirect effects of an aid program: How do cash transfers affect ineligibles' consumption? American Economic Review, 99(1):486508.

Ardington, C., Case, A., and Hosegood, V. (2009). Labor supply responses to large social transfers: Longitudinal evidence from South Africa. American Economic Journal: Applied Economics, 1(1):22-48.

Arnold, C., Conway, T., and Greenslade, M. (2011). Cash transfers evidence paper. London: Department for International Development. 
Baele, S. J. and Sterck, O. C. (2015). Diagnosing the securitisation of immigration at the EU level: A new method for stronger empirical claims. Political Studies, 63(5):11201139.

Bah, T. L. and Batista, C. (2018). Understanding willingness to migrate illegally: Evidence from a lab in the field experiment. Technical report, Universidade Nova de Lisboa, Faculdade de Economia, NOVAFRICA.

Baird, S., McKenzie, D., and Özler, B. (2018). The effects of cash transfers on adult labor market outcomes. IZA Journal of Development and Migration, 8(1):22.

Bastagli, F., Hagen-Zanker, J., Harman, L., Barca, V., Sturge, G., Schmidt, T., and Pellerano, L. (2016). Cash transfers: what does the evidence say? A rigorous review of programme impact and of the role of design and implementation features. London: ODI.

Batista, C. and McKenzie, D. (2018). Testing classic theories of migration in the lab. Technical report, Universidade Nova de Lisboa, Faculdade de Economia, NOVAFRICA.

Bazzi, S. (2017). Wealth heterogeneity and the income elasticity of migration. American Economic Journal: Applied Economics, 9(2):219-55.

Beegle, K., Galasso, E., and Goldberg, J. (2017). Direct and indirect effects of Malawi's public works program on food security. Journal of Development Economics, 128:1-23.

Benjamini, Y., Krieger, A. M., and Yekutieli, D. (2006). Adaptive linear step-up procedures that control the false discovery rate. Biometrika, 93(3):491-507.

Bertoli, S. and Murard, E. (2019). Migration and co-residence choices: Evidence from Mexico. Journal of Development Economics.

Blanchy, S. (2002). Mayotte: Française à tout prix. Ethnologie française, 32(4):677-687. 
Bryan, G., Chowdhury, S., and Mobarak, A. M. (2014). Underinvestment in a profitable technology: The case of seasonal migration in Bangladesh. Econometrica, 82(5):16711748.

Cahyadi, N., Hanna, R., Olken, B. A., Prima, R. A., Satriawan, E., and Syamsulhakim, E. (2020). Cumulative impacts of conditional cash transfer programs: Experimental evidence from Indonesia. American Economic Journal: Economic Policy. Forthcoming.

Cai, S. (2018). Migration under liquidity constraints: Evidence from randomized credit access in China. Journal of Development Economics.

Clemens, M. A. (2011). Economics and emigration: Trillion-dollar bills on the sidewalk? Journal of Economic Perspectives, 25(3):83-106.

Clemens, M. A. et al. (2014). Does development reduce migration. International Handbook on Migration and Economic development, pages 152-185.

Clemens, M. A. and Postel, H. M. (2018). Deterring emigration with foreign aid: An overview of evidence from low-income countries. Population and Development Review, 44(4):667-693.

Cunha, J. M., De Giorgi, G., and Jayachandran, S. (2018). The price effects of cash versus in-kind transfers. The Review of Economic Studies, 86(1):240-281.

Dao, T. H., Docquier, F., Parsons, C., and Peri, G. (2018). Migration and development: Dissecting the anatomy of the mobility transition. Journal of Development Economics, 132:88-101.

D'Aoust, O., Sterck, O., Verwimp, P., et al. (2018). Who benefited from Burundi's demobilization program? World Bank Economic Review, 32(2):357-382.

Delius, A. and Sterck, O. (2020). Cash Transfers and Micro-Enterprise Performance: Theory and Quasi-Experimental Evidence from Kenya. CSAE Working Paper WPS/2020-09. 
Dohmen, T., Falk, A., Huffman, D., Sunde, U., Schupp, J., and Wagner, G. G. (2011). Individual risk attitudes: Measurement, determinants, and behavioral consequences. Journal of the European Economic Association, 9(3):522-550.

Dustmann, C., Fasani, F., Meng, X., and Minale, L. (2017). Risk attitudes and household migration decisions. Centro Studi Luca d'Agliano Development Studies Working Paper, (423).

Dustmann, C., Vasiljeva, K., and Piil Damm, A. (2018). Refugee migration and electoral outcomes. The Review of Economic Studies, 86(5):2035-2091.

Egger, D., Haushofer, J., Miguel, E., Niehaus, P., and Walker, M. W. (2019). General equilibrium effects of cash transfers: experimental evidence from kenya. National Bureau of Economic Research.

Eggleston, K., Sun, A., and Zhan, Z. (2016). The impact of rural pensions in China on labor migration. The World Bank Economic Review, 32(1):64-84.

Esipova, N., Pugliese, A., and Ray, J. (2018). More than 750 million worldwide would migrate if they could. Washington DC:'Gallup World, 10.

Filmer, D., Friedman, J., Kandpal, E., and Onishi, J. (2018). General equilibrium effects of targeted cash transfers: Nutrition impacts on non-beneficiary children. World Bank Policy Research Working Paper Series.

Gazeaud, J., Mvukiyehe, E., and Sterck, O. (2019). Public works and welfare: A randomized control trial of the Comoros social safety net project-endline report. Technical report, The World Bank.

Gehrke, E. and Hartwig, R. (2018). Productive effects of public works programs: What do we know? What should we know? World development, 107:111-124.

Gentilini, U., Almenfi, M., Orton, I., and Dale, P. (2020). Social protection and jobs responses to covid-19: A real-time review of country measures. live document. world bank, washington, dc. 
Giambra, S. and McKenzie, D. J. (2019). Self-employment and migration. Technical report, The World Bank.

Gibson, J. and McKenzie, D. (2011). The microeconomic determinants of emigration and return migration of the best and brightest: Evidence from the Pacific. Journal of Development Economics, 1(95):18-29.

Gibson, J. and McKenzie, D. (2012). The economic consequences of 'brain drain'of the best and brightest: Microeconomic evidence from five countries. The Economic Journal, 122(560):339-375.

Goldbach, C. and Schlüter, A. (2018). Risk aversion, time preferences, and outmigration. Experimental evidence from Ghana and Indonesia. Journal of Economic Behavior E Organization, 150:132-148.

Guiso, L. and Paiella, M. (2008). Risk aversion, wealth, and background risk. Journal of the European Economic association, 6(6):1109-1150.

Halla, M., Wagner, A. F., and Zweimüller, J. (2017). Immigration and voting for the far right. Journal of the European Economic Association, 15(6):1341-1385.

Haushofer, J. and Shapiro, J. (2016). The short-term impact of unconditional cash transfers to the poor: Experimental evidence from Kenya. The Quarterly Journal of Economics, 131(4):1973-2042.

Honorati, M., Gentilini, U., and Yemtsov, R. G. (2015). The state of social safety nets 2015. Washington, DC: World Bank Group.

Imbert, C. and Papp, J. (2019). Short-term migration, rural public works and urban labor markets: Evidence from India. Journal of the European Economic Association. Forthcoming.

Jaeger, D. A., Dohmen, T., Falk, A., Huffman, D., Sunde, U., and Bonin, H. (2010). Direct evidence on risk attitudes and migration. The Review of Economics and Statistics, 92(3):684-689. 
Kaestner, R. and Malamud, O. (2014). Self-selection and international migration: New evidence from Mexico. Review of Economics and Statistics, 96(1):78-91.

Keen, D. and Andersson, R. (2018). Double games: Success, failure and the relocation of risk in fighting terror, drugs and migration. Political Geography, 67:100-110.

Kleemans, M. (2015). Migration choice under risk and liquidity constraints. Technical report, Agricultural and Applied Economics Association.

Kleemans, M. and Magruder, J. (2017). Labour market responses to immigration: Evidence from internal migration driven by weather shocks. The Economic Journal, 128(613):2032-2065.

Le Monde (2017). "M. Macron, les kwassa-kwassa ont fait plus de 10000 morts". Opinion column - Hachim Sä̈d Hassane.

MacPherson, C. and Sterck, O. (2019). Humanitarian vs. development aid for refugees: Evidence from a regression discontinuity design. CSAE Working Paper WPS/2019 15.

Mahajan, P. and Yang, D. (2017). Taken by storm: Hurricanes, migrant networks, and US immigration. National Bureau of Economic Research Working Paper.

Marie, C.-V., Breton, D., Crouzet, M., Fabre, E., Merceron, S., et al. (2017). Migrations, natalité et solidarités familiales. La société de Mayotte en pleine mutation. Insee La Réunion-Mayotte.

Mayda, A. M., Peri, G., and Steingress, W. (2018). The political impact of immigration: Evidence from the United States. Technical report, National Bureau of Economic Research.

McKenzie, D., Stillman, S., and Gibson, J. (2010). How important is selection? Experimental vs. non-experimental measures of the income gains from migration. Journal of the European Economic Association, 8(4):913-945.

Meghir, C., Mobarak, A. M., Mommaerts, C. D., and Morten, M. (2019). Migration and informal insurance. Technical report, National Bureau of Economic Research. 
Millán, T. M., Barham, T., Macours, K., Maluccio, J. A., and Stampini, M. (2019). Longterm impacts of conditional cash transfers: review of the evidence. The World Bank Research Observer, 34(1):119-159.

Morten, M. (2019). Temporary migration and endogenous risk sharing in village India. Journal of Political Economy, 127(1):1-46.

Sénat (2001). Projet de loi relatif à Mayotte. Rapport Sénat 361.

Sénat (2008). L'immigration clandestine à Mayotte. Rapport Sénat 461.

Sénat (2012). Rapport d'information. Rapport Sénat 675.

Shrestha, M. (2019a). Death scares: How potential work-migrants infer mortality rates from migrant deaths. Journal of Development Economics, 141:102368.

Shrestha, M. (2019b). Get rich or die tryin': Perceived earnings, perceived mortality rates, and migration decisions of potential work migrants from nepal. The World Bank Economic Review.

Stecklov, G., Winters, P., Stampini, M., and Davis, B. (2005). Do conditional cash transfers influence migration? A study using experimental data from the Mexican PROGRESA program. Demography, 42(4):769-790.

Sterck, O. (2019). Beyond the stars. Journal of Economic Surveys, 33(5):1409-1436.

United Nations (2019). International Migrant Stock 2019. United Nations, Department of Economic and Social Affairs, Population Division: New York.

van Huizen, T. and Alessie, R. (2019). Risk aversion and job mobility. Journal of Economic Behavior E Organization, 164:91-106. 


\section{Online Appendix}

\section{A Supplementary tables and figures}

Table A1: Poverty rates in treated villages

\begin{tabular}{lcccc}
\hline \hline & \multicolumn{2}{c}{ Non-CFW villages } & \multicolumn{2}{c}{ CFW villages } \\
& Pop (hh) & Poverty rate & Pop (hh) & Poverty rate \\
\hline Grande Comore & 42,744 & $41.3 \%$ & 5,435 & $80.6 \%$ \\
Anjouan & 38,152 & $41.5 \%$ & 4,778 & $95.6 \%$ \\
Moheli & 4,987 & $55.0 \%$ & 1,097 & $94.8 \%$ \\
Total & 85,883 & $42.1 \%$ & 11,310 & $88.2 \%$ \\
\hline
\end{tabular}

Notes: Authors' calculations based on the 2003/04 poverty mapping.

Figure A1: Timeline diagram

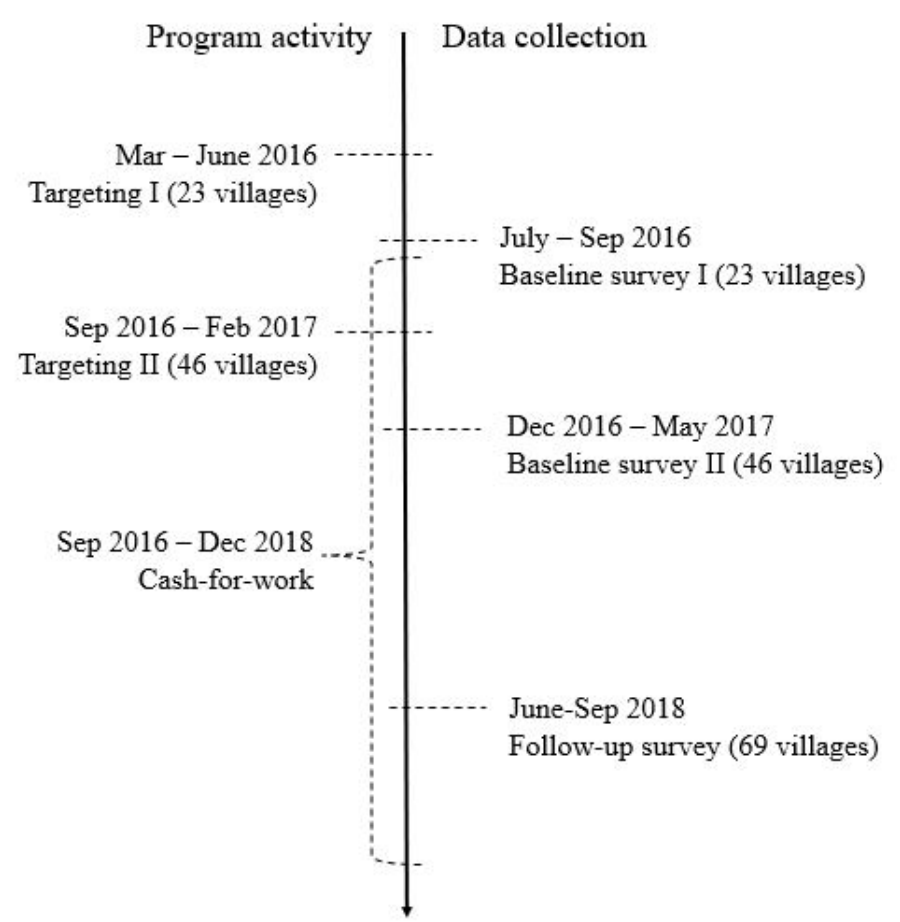

Source: Authors' elaboration 
Table A2: LATE estimates

\begin{tabular}{lcccccccc}
\hline \hline & \multicolumn{3}{c}{$\begin{array}{c}\text { Migration } \\
\text { (excl. returns) }\end{array}$} & & \multicolumn{3}{c}{$\begin{array}{c}\text { Migration } \\
\text { (incl. returns) }\end{array}$} \\
\cline { 2 - 4 } \cline { 7 - 9 } & $(1)$ & $(2)$ & $(3)$ & & $(4)$ & $(5)$ & $(6)$ \\
\hline Treatment & $0.051^{* *}$ & $0.049^{* *}$ & $0.048^{* *}$ & & $0.063^{* *}$ & $0.060^{* *}$ & $0.059^{* *}$ \\
& $(0.022)$ & $(0.021)$ & $(0.021)$ & & $(0.026)$ & $(0.025)$ & $(0.025)$ \\
\hline Extended controls & No & Yes & Yes & & No & Yes & Yes \\
Island FE & No & No & Yes & & No & No & Yes \\
Control mean & 0.078 & 0.078 & 0.078 & & 0.128 & 0.128 & 0.128 \\
Observations & 2181 & 2181 & 2181 & & 2181 & 2181 & 2181 \\
\hline
\end{tabular}

Notes: This table reports LATE estimates of the program. Random assignment is used as an IV for actually treated households (according to survey data). See notes to Table 3 for other details. Robust standard errors are in parentheses. ${ }^{* *} p<0.01,{ }^{* *} p<0.05, *$ $\mathrm{p}<0.1$.

Table A3: Estimating the income elasticity of migration

\begin{tabular}{|c|c|c|c|c|c|c|}
\hline & \multicolumn{3}{|c|}{$\begin{array}{c}\text { Migration } \\
\text { (excl. returns) }\end{array}$} & \multicolumn{3}{|c|}{$\begin{array}{c}\text { Migration } \\
\text { (incl. returns) }\end{array}$} \\
\hline & (1) & (2) & (3) & (4) & (5) & (6) \\
\hline $\begin{array}{l}\text { Second-stage regression } \\
\text { Income (in } \mathrm{log} \text { ) }\end{array}$ & $\begin{array}{l}0.080^{*} \\
(0.047)\end{array}$ & $\begin{array}{l}0.065^{*} \\
(0.038)\end{array}$ & $\begin{array}{l}0.064^{*} \\
(0.038)\end{array}$ & $\begin{array}{l}0.103^{*} \\
(0.058)\end{array}$ & $\begin{array}{l}0.084^{*} \\
(0.046)\end{array}$ & $\begin{array}{l}0.082^{*} \\
(0.046)\end{array}$ \\
\hline $\begin{array}{l}\text { First-stage (dep. var.: log income) } \\
\text { Treatment }\end{array}$ & $\begin{array}{c}0.306^{* * *} \\
(0.069)\end{array}$ & $\begin{array}{c}0.344^{* * *} \\
(0.057)\end{array}$ & $\begin{array}{l}0.345^{* * *} \\
(0.057)\end{array}$ & $\begin{array}{c}0.306^{* * *} \\
(0.069)\end{array}$ & $\begin{array}{l}0.344^{* * * *} \\
(0.057)\end{array}$ & $\begin{array}{c}0.345^{* * *} \\
(0.057)\end{array}$ \\
\hline $\begin{array}{l}\text { Income elasticity of migration } \\
\text { KPW F-test (first-stage) } \\
\text { Extended controls } \\
\text { Island FE } \\
\text { Control mean } \\
\text { Observations }\end{array}$ & $\begin{array}{l}1.03 \\
19.78 \\
\text { No } \\
\text { No } \\
0.078 \\
1937\end{array}$ & $\begin{array}{c}0.83 \\
36.50 \\
\text { Yes } \\
\text { No } \\
0.078 \\
1937\end{array}$ & $\begin{array}{c}0.82 \\
37.16 \\
\text { Yes } \\
\text { Yes } \\
0.078 \\
1937\end{array}$ & $\begin{array}{c}0.80 \\
19.78 \\
\text { No } \\
\text { No } \\
0.128 \\
1937\end{array}$ & $\begin{array}{c}0.65 \\
36.50 \\
\text { Yes } \\
\text { No } \\
0.128 \\
1937\end{array}$ & $\begin{array}{c}0.64 \\
37.16 \\
\text { Yes } \\
\text { Yes } \\
0.128 \\
1937\end{array}$ \\
\hline
\end{tabular}

Notes: This table reports estimates of the income elasticity of migration, using the random assignment to the treatment as an instrument for income. The average income elasticity of migration is obtained by dividing the regression coefficient on log income by the average migration rate in the control group. Households reporting no income at baseline are excluded from these estimates. See notes to Table 3 for other details. Robust standard errors are in parentheses. ${ }^{* * *} \mathrm{p}<0.01,{ }^{* *}$ $\mathrm{p}<0.05,{ }^{*} \mathrm{p}<0.1$.

Table A4: Treatment effects on remittances

\begin{tabular}{|c|c|c|c|c|c|c|}
\hline & \multicolumn{3}{|c|}{$\begin{array}{l}\text { Remittances } \\
\text { (dummy) }\end{array}$} & \multicolumn{3}{|c|}{$\begin{array}{c}\text { Remittances } \\
\text { (amount sent) }\end{array}$} \\
\hline & (1) & (2) & (3) & (4) & (5) & (6) \\
\hline Treatment & $\begin{array}{c}0.010 \\
(0.006)\end{array}$ & $\begin{array}{c}0.009 \\
(0.006)\end{array}$ & $\begin{array}{c}0.008 \\
(0.006)\end{array}$ & $\begin{array}{l}0.121^{*} \\
(0.070)\end{array}$ & $\begin{array}{c}0.110 \\
(0.069)\end{array}$ & $\begin{array}{c}0.107 \\
(0.069)\end{array}$ \\
\hline Extended controls & No & Yes & Yes & No & Yes & Yes \\
\hline Island FE & No & No & Yes & No & No & Yes \\
\hline Control mean & 0.016 & 0.016 & 0.016 & 0.175 & 0.175 & 0.175 \\
\hline Observations & 2163 & 2163 & 2163 & 2163 & 2163 & 2163 \\
\hline
\end{tabular}

Notes: The dependent variable in columns 1 to 3 is a dummy equal to one if the migrant sent remittances to his or her household of origin. The dependent variable in columns 4 to 6 equals the amount of the remittances. An inverse hyperbolic sine (IHS) transformation has been applied to the amount of the remittances. We do not have information on remittances sent by return migrants during their time in Mayotte. Robust standard errors are in parentheses. ${ }^{* * *} \mathrm{p}<0.01,{ }^{* *} \mathrm{p}<0.05,{ }^{*} \mathrm{p}<0.1$. 


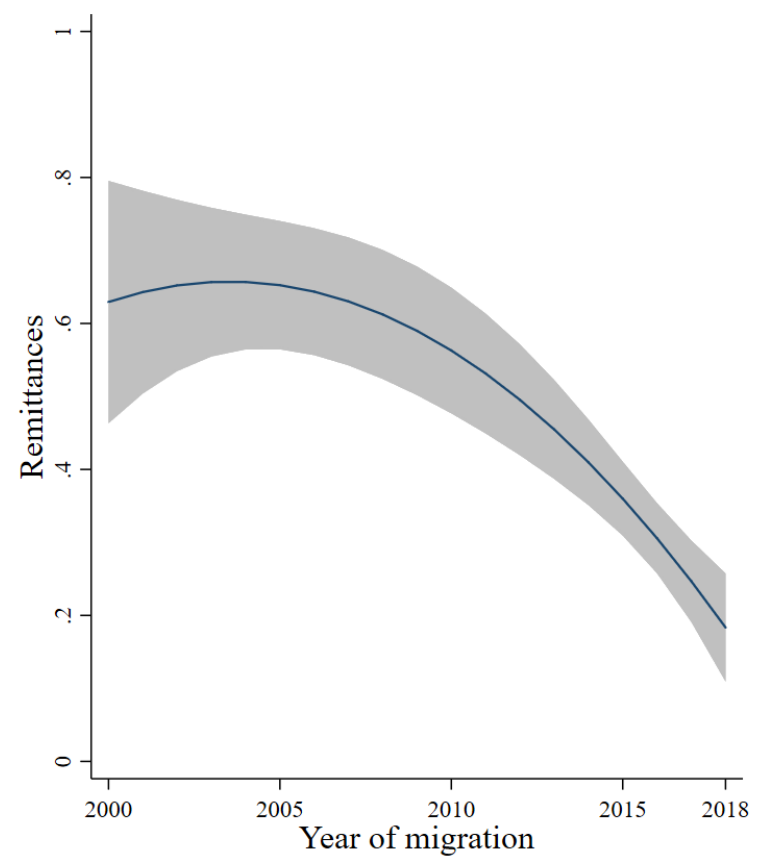

Figure A2: Year of migration and remittances

Notes: This figure shows the likelihood that a migrant in Mayotte remit to her household of origin depending on her year of migration. The estimate is derived using the sample of households with a person in Mayotte at follow-up $(\mathrm{N}=437)$ and a fractional-polynomial prediction. For each migrants reported by the household, we asked her year of migration and whether she remitted in the 12 months prior to the survey. 
Table A5: Differential attrition test

\begin{tabular}{lcccccc}
\hline \hline & \multicolumn{2}{c}{ Control } & \multicolumn{2}{c}{ Treatment } & & \\
& Mean & SD & Mean & SD & Diff & p-value \\
\hline Attrition rate & 0.044 & 0.206 & 0.037 & 0.189 & 0.007 & 0.39 \\
Observations & 900 & 900 & 1372 & 1372 & 2272 & 2272 \\
\hline
\end{tabular}

Notes: This table displays the difference in mean attrition between treatment and control groups.

Table A6: Attrition reasons

\begin{tabular}{lcccccc}
\hline \hline & \multicolumn{2}{c}{ Control } & \multicolumn{2}{c}{ Treatment } & & \\
& Mean & SD & Mean & SD & Diff & p-value \\
\hline Attrition reason & & & & & & \\
$\quad$ Duplicate household & 0.002 & 0.047 & 0.002 & 0.047 & 0.000 & 0.99 \\
$\quad$ Refusal & 0.007 & 0.081 & 0.004 & 0.066 & 0.002 & 0.46 \\
Absent & 0.009 & 0.094 & 0.009 & 0.093 & 0.000 & 0.97 \\
Dissolved household & 0.020 & 0.140 & 0.019 & 0.136 & 0.001 & 0.86 \\
Too sick & 0.001 & 0.033 & 0.001 & 0.027 & 0.000 & 0.76 \\
$\quad$ Other & 0.006 & 0.074 & 0.002 & 0.047 & 0.003 & 0.19 \\
\hline Observations & 900 & 900 & 1372 & 1372 & 2272 & 2272 \\
\hline
\end{tabular}

Notes: This table displays difference in mean attrition rates between treatment and control groups by attrition reasons. 
Table A7: Indirect treatment effects

\begin{tabular}{|c|c|c|c|c|c|c|}
\hline & \multicolumn{3}{|c|}{$\begin{array}{c}\text { Migration } \\
\text { (excl. returns) }\end{array}$} & \multicolumn{3}{|c|}{$\begin{array}{c}\text { Migration } \\
\text { (incl. returns) }\end{array}$} \\
\hline & (1) & $(2)$ & (3) & $(4)$ & (5) & (6) \\
\hline \multirow[t]{2}{*}{ Treatment } & 0.033 & 0.034 & $0.033^{*}$ & 0.032 & 0.034 & 0.033 \\
\hline & $(0.022)$ & $(0.021)$ & $(0.017)$ & $(0.028)$ & $(0.027)$ & $(0.021)$ \\
\hline \multirow[t]{2}{*}{$40 \%$ villages $\left(\beta_{2}\right)$} & -0.002 & 0.006 & 0.000 & -0.007 & 0.005 & -0.004 \\
\hline & $(0.023)$ & $(0.018)$ & $(0.018)$ & $(0.028)$ & $(0.024)$ & $(0.022)$ \\
\hline \multirow[t]{2}{*}{ Treatment $x 40 \%$ villages $\left(\beta_{3}\right)$} & -0.006 & -0.011 & -0.010 & 0.009 & 0.000 & 0.002 \\
\hline & $(0.026)$ & $(0.024)$ & $(0.024)$ & $(0.036)$ & $(0.034)$ & $(0.029)$ \\
\hline \multirow[t]{2}{*}{$\beta_{2}+\beta_{3}$} & -0.007 & -0.006 & -0.010 & 0.002 & 0.005 & -0.002 \\
\hline & $(0.024)$ & $(0.019)$ & $(0.016)$ & $(0.031)$ & $(0.024)$ & $(0.020)$ \\
\hline Extended controls & No & Yes & Yes & No & Yes & Yes \\
\hline Island FE & No & No & Yes & No & No & Yes \\
\hline Control mean (in $20 \%$ villages) & 0.079 & 0.079 & 0.079 & 0.131 & 0.131 & 0.131 \\
\hline Observations & 2181 & 2181 & 2181 & 2181 & 2181 & 2181 \\
\hline
\end{tabular}

Notes: This table reports LPM estimates of indirect treatment effects using equation 2]. See notes to Table 3 for other details. Standard errors in parentheses are clustered at the village level. ${ }^{* * *} \mathrm{p}<0.01,{ }^{* *} \mathrm{p}<0.05,{ }^{*} \mathrm{p}<0.1$.

Table A8: Corrections for multiple hypothesis testing

\begin{tabular}{|c|c|c|c|c|c|c|c|c|c|c|c|c|}
\hline & $\begin{array}{c}(1) \\
\text { Total } \\
\text { number of } \\
\text { days } \\
\text { worked } \\
\end{array}$ & $\begin{array}{c}(2) \\
\text { Total } \\
\text { income }\end{array}$ & $\begin{array}{c}\text { (3) } \\
\text { Total food } \\
\text { expendi- } \\
\text { tures }\end{array}$ & $\begin{array}{c}(4) \\
\text { Total } \\
\text { non-food } \\
\text { expendi- } \\
\text { tures }\end{array}$ & $\begin{array}{c}5) \\
\text { Food } \\
\text { security } \\
\text { index }\end{array}$ & $\begin{array}{l}6) \\
\text { Asset } \\
\text { index }\end{array}$ & $\begin{array}{c}(7) \\
\text { Financial } \\
\text { index }\end{array}$ & $\begin{array}{c}(8) \\
\text { Migration } \\
\text { to } \\
\text { Mayotte }\end{array}$ & $\begin{array}{c}\text { (9) } \\
\text { Social and } \\
\text { political } \\
\text { index }\end{array}$ & $\begin{array}{c}(10) \\
\text { Conflict } \\
\text { crime and } \\
\text { violence } \\
\text { index }\end{array}$ & $\begin{array}{l}\text { (11) } \\
\text { Gender- } \\
\text { based } \\
\text { violence } \\
\text { index }\end{array}$ & $\begin{array}{c}\text { (12) } \\
\text { Psycho. } \\
\text { index }\end{array}$ \\
\hline Treatment & $\begin{array}{c}5.291^{* * *} \\
(1.556)\end{array}$ & $\begin{array}{c}1.030^{* * *} \\
(0.129)\end{array}$ & $\begin{array}{l}-0.441 \\
(0.470)\end{array}$ & $\begin{array}{l}-0.965 \\
(0.842)\end{array}$ & $\begin{array}{c}-0.026 \\
(0.020)\end{array}$ & $\begin{array}{c}-0.021 \\
(0.018)\end{array}$ & $\begin{array}{c}-0.012 \\
(0.017)\end{array}$ & $\begin{array}{c}0.028^{* *} \\
(0.012)\end{array}$ & $\begin{array}{c}0.009 \\
(0.009)\end{array}$ & $\begin{array}{c}0.005 \\
(0.010)\end{array}$ & $\begin{array}{c}0.027 \\
(0.018)\end{array}$ & $\begin{array}{c}-0.013 \\
(0.015)\end{array}$ \\
\hline $\begin{array}{l}\text { p-value } \\
\text { q-value ( } 8 \text { outcomes) } \\
\text { q-value ( } 12 \text { outcomes) }\end{array}$ & $\begin{array}{l}{[0.001]} \\
{[0.003]} \\
{[0.004]}\end{array}$ & $\begin{array}{l}{[0.000]} \\
{[0.001]} \\
{[0.001]}\end{array}$ & $\begin{array}{l}{[0.348]} \\
{[0.331]} \\
{[0.534]}\end{array}$ & $\begin{array}{l}{[0.252]} \\
{[0.267]} \\
{[0.480]}\end{array}$ & $\begin{array}{l}{[0.198]} \\
{[0.267]} \\
{[0.480]}\end{array}$ & $\begin{array}{l}{[0.234]} \\
{[0.267]} \\
{[0.480]}\end{array}$ & $\begin{array}{l}{[0.474]} \\
{[0.422]} \\
{[0.635]}\end{array}$ & $\begin{array}{l}{[0.019]} \\
{[0.040]} \\
{[0.068]}\end{array}$ & [0.340] & {$[0.630]$} & {$[0.144]$} & [0.401] \\
\hline $\begin{array}{l}\text { Control mean } \\
\text { Observations }\end{array}$ & $\begin{array}{c}53.805 \\
2181\end{array}$ & $\begin{array}{l}3.587 \\
2181\end{array}$ & $\begin{array}{c}38.037 \\
2181\end{array}$ & $\begin{array}{c}82.732 \\
2181\end{array}$ & $\begin{array}{l}0.000 \\
2181\end{array}$ & $\begin{array}{l}0.000 \\
2181\end{array}$ & $\begin{array}{l}0.000 \\
2181\end{array}$ & $\begin{array}{l}0.078 \\
2181\end{array}$ & $\begin{array}{l}0.000 \\
2181\end{array}$ & $\begin{array}{l}0.000 \\
2181\end{array}$ & $\begin{array}{l}0.000 \\
1761\end{array}$ & $\begin{array}{l}0.000 \\
2181\end{array}$ \\
\hline
\end{tabular}




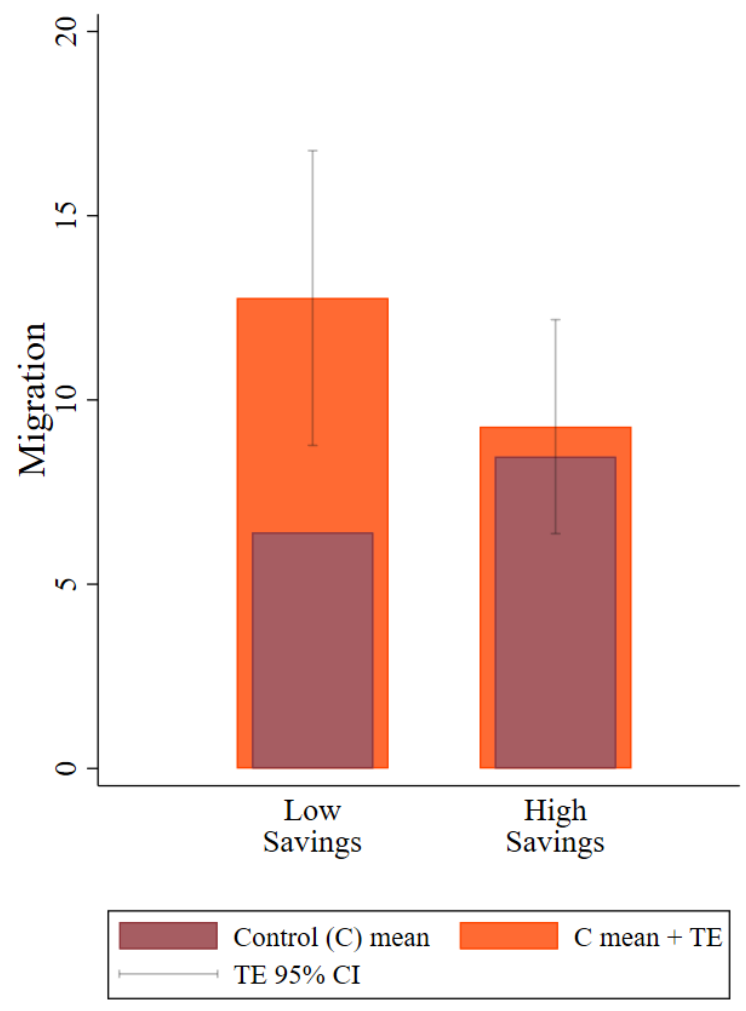

Figure A3: Liquidity channel

Notes: This figure shows follow-up household migration rates conditional on baseline savings. Households are divided in two groups depending on their levels of savings at baseline. Low (resp. high) savings correspond to savings below (resp. above) mean savings. An IHS transformation was applied in order to limit the influence of outliers. Treatment effects and $95 \%$ confidence intervals are derived from the estimates of Equation (3) including all controls (balanced covariates, island fixed effects, and their interactions with savings). $\mathrm{N}=2181$. 


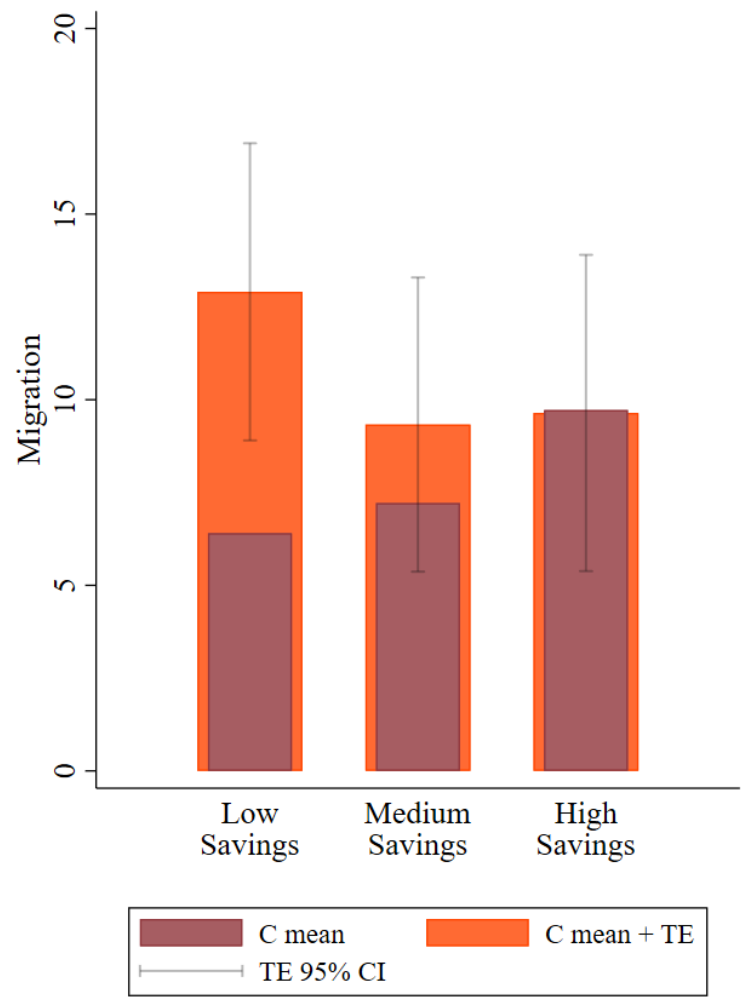

Figure A4: Liquidity channel - three groups

Notes: This figure shows follow-up household migration rates conditional on baseline savings. Households are divided in three groups of equal size. An IHS transformation was applied in order to limit the influence of outliers. Treatment effects and 95\% confidence intervals are derived from the estimates of Equation (3) including all controls (balanced covariates, island fixed effects, and their interactions with savings). $\mathrm{N}=2181$. 
Table A9: Other migration patterns

\begin{tabular}{lcccc}
\hline \hline & $\begin{array}{c}(1) \\
\text { Domestic Mig. } \\
\text { (intra-island) }\end{array}$ & $\begin{array}{c}(2) \\
\text { Domestic Mig. } \\
\text { (inter-island) }\end{array}$ & $\begin{array}{c}(3) \\
\text { Migration } \\
\text { France }\end{array}$ & $\begin{array}{c}\text { Migration } \\
\text { Other }\end{array}$ \\
\hline Treatment & -0.023 & 0.007 & -0.001 & 0.002 \\
& $(0.018)$ & $(0.010)$ & $(0.007)$ & $(0.007)$ \\
\hline Extended controls & Yes & Yes & Yes & Yes \\
Island FE & Yes & Yes & Yes & Yes \\
Control mean & 0.236 & 0.057 & 0.029 & 0.030 \\
Observations & 2181 & 2181 & 2181 & 2181 \\
\hline
\end{tabular}

Notes: Robust standard errors are in parentheses. ${ }^{* *} \mathrm{p}<0.01,{ }^{* *} \mathrm{p}<0.05,{ }^{*} \mathrm{p}<0.1$. See notes to Table 3 for more details.

Table A10: Summary statistics on project workers and migrants

\begin{tabular}{|c|c|c|c|c|c|c|c|c|c|c|}
\hline & (1) & $(2)$ & (3) & $(4)$ & (5) & (6) & (7) & (8) & (9) & (10) \\
\hline & \multicolumn{3}{|c|}{ Treated } & Controls & \multicolumn{6}{|c|}{ p-value diff. } \\
\hline & \multicolumn{2}{|c|}{ Non-migrants } & \multirow[t]{2}{*}{ Migrants } & \multirow[t]{2}{*}{ Migrants } & \multirow[t]{2}{*}{ (1) vs. (2) } & \multirow[t]{2}{*}{ (1) vs. (3) } & \multirow[t]{2}{*}{ (1) vs. (4) } & \multirow[t]{2}{*}{ (2) vs. (3) } & \multirow[t]{2}{*}{ (2) vs. (4) } & \multirow[t]{2}{*}{ (3) vs. (4) } \\
\hline & Worker $=1$ & Worker $=0$ & & & & & & & & \\
\hline Age & 39.56 & 30.29 & 28.73 & 29.18 & $0.00^{* * *}$ & $0.00^{* * *}$ & $0.00^{* * *}$ & $0.09^{*}$ & 0.36 & 0.76 \\
\hline Male & 0.22 & 0.60 & 0.59 & 0.56 & $0.00^{* * *}$ & $0.00^{* * *}$ & $0.00^{* * *}$ & 0.83 & 0.45 & 0.62 \\
\hline \multicolumn{11}{|l|}{ Education } \\
\hline Did not complete primary & 0.56 & 0.26 & 0.28 & 0.25 & $0.00^{* * *}$ & $0.00^{* * *}$ & $0.00^{* * *}$ & 0.83 & 0.45 & 0.62 \\
\hline Primary & 0.25 & 0.19 & 0.28 & 0.35 & $0.00^{* * *}$ & 0.40 & $0.03^{* *}$ & $0.01^{* *}$ & $0.00^{* * *}$ & 0.18 \\
\hline Secondary & 0.17 & 0.44 & 0.38 & 0.33 & $0.00^{* * *}$ & $0.00^{* * *}$ & $0.00^{* * *}$ & 0.14 & $0.03^{* *}$ & 0.39 \\
\hline Tertiary & 0.03 & 0.11 & 0.06 & 0.07 & $0.00^{* * *}$ & $0.05^{*}$ & 0.11 & $0.00^{* * *}$ & $0.05^{*}$ & 0.86 \\
\hline IGA & 0.24 & 0.20 & 0.14 & 0.22 & $0.00^{* * *}$ & $0.00^{* * *}$ & 0.59 & $0.04^{* *}$ & 0.57 & 0.11 \\
\hline Migration experience & 0.07 & 0.06 & 0.29 & 0.30 & $0.09^{*}$ & $0.00^{* * *}$ & $0.00^{* * *}$ & $0.00^{* * *}$ & $0.00^{* * *}$ & 0.73 \\
\hline Observations & 991 & 3166 & 196 & 105 & 4157 & 1187 & 1096 & 3362 & 3271 & 301 \\
\hline
\end{tabular}

Notes: The sample is restricted to adults (15-65 at baseline). Columns (5)-(10) report the pvalue of a t-test of mean equality across subsamples. ${ }^{* * *} \mathrm{p}<0.01, * *$ $\mathrm{p}<0.05,{ }^{*} \mathrm{p}<0.1$. 
Table A11: Treatment effects on debts

\begin{tabular}{lccc}
\hline \hline & \multicolumn{3}{c}{ Debts } \\
\cline { 2 - 4 } & $(1)$ & $(2)$ & $(3)$ \\
\hline Treatment & 0.062 & 0.054 & 0.057 \\
& $(0.258)$ & $(0.250)$ & $(0.248)$ \\
\hline Extended controls & No & Yes & Yes \\
Island FE & No & No & Yes \\
Control mean & 8.220 & 8.220 & 8.220 \\
Observations & 2181 & 2181 & 2181 \\
\hline Notes: This table reports estimates of equation & 1 using the
\end{tabular}

Notes: This table reports estimates of equation 1 using the level of debt at follow-up as outcome variable. To account for potential outliers, an IHS transformation has been applied. Robust standard errors are in parentheses. ${ }^{* *} p<0.01,{ }^{* *} p<0.05$, * $\mathrm{p}<0.1$.

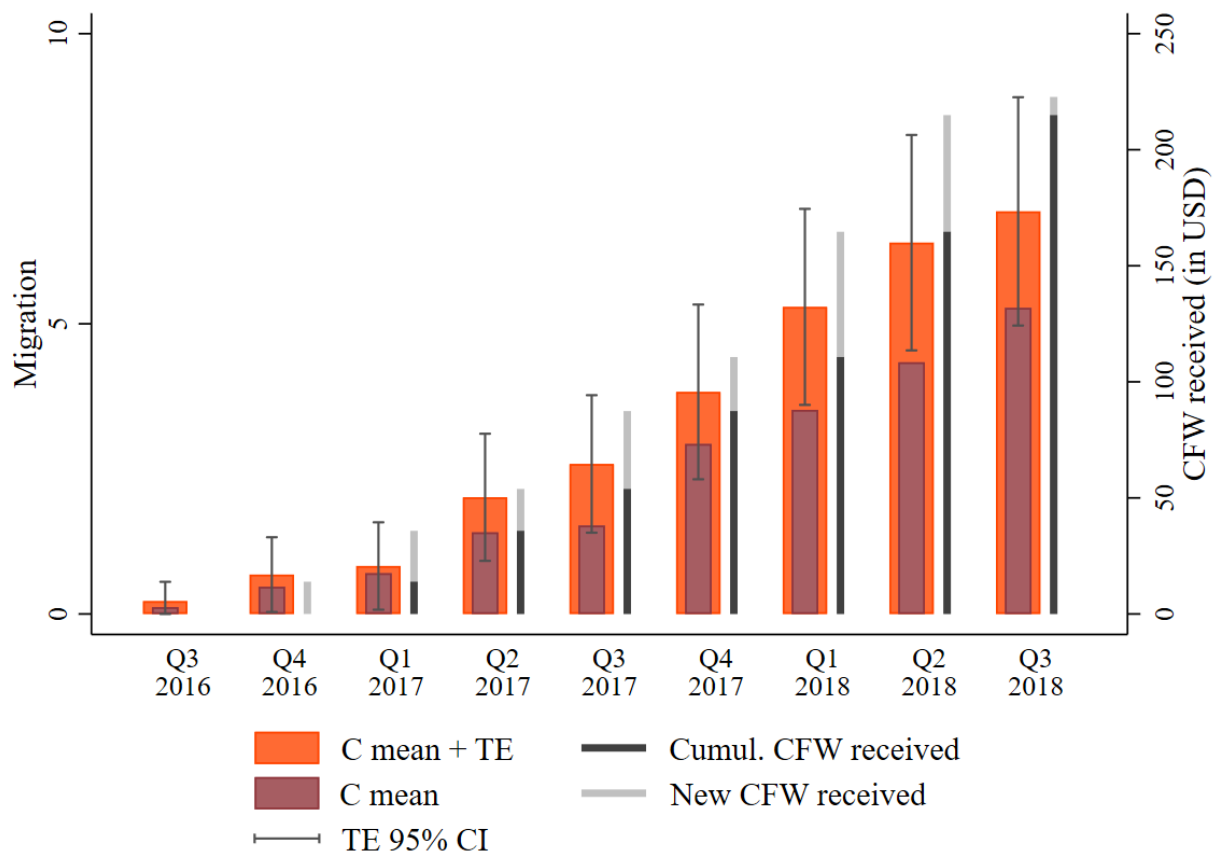

Figure A5: Treatment effect over time

Notes: This figure shows the evolution of follow-up households' migration rates over time. Treatment effects and 95\% confidence intervals are derived from the estimate of equation (1) including all controls (extended covariates and island fixed effects). $\mathrm{N}=2181$. 


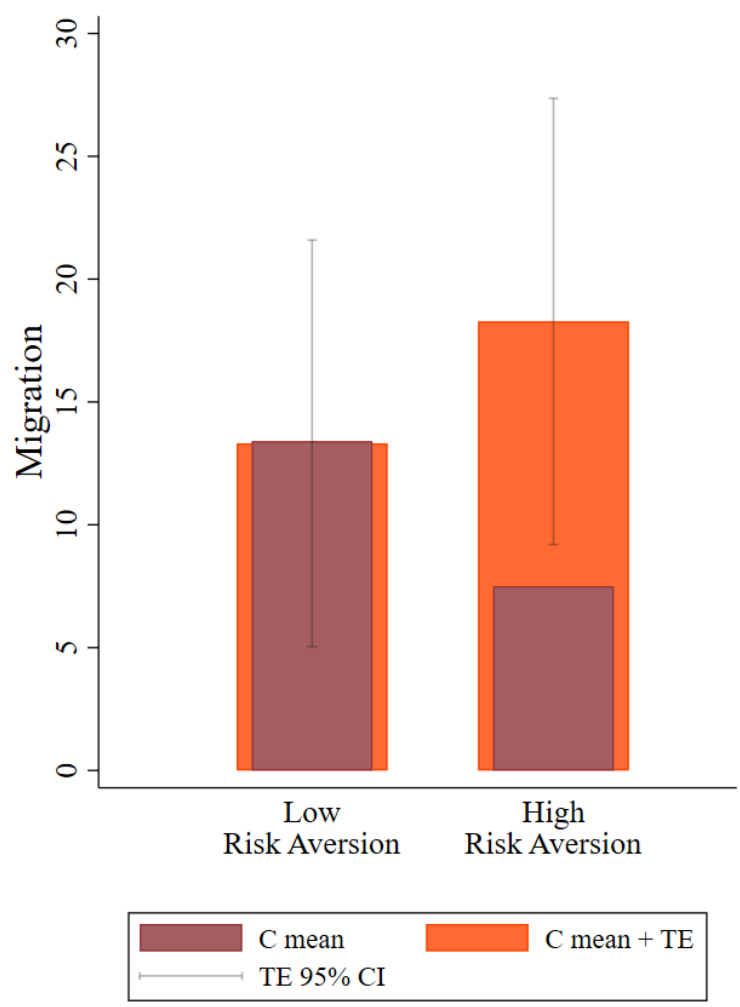

Figure A6: Risk-aversion channel

Notes: This figure shows follow-up household migration rates conditional on baseline risk-aversion. Households are divided in two groups depending on their levels of risk-aversion at baseline. Low (resp. high) risk-aversion corresponds to risk-aversion below (resp. above) mean risk-aversion. Treatment effects and 95\% confidence intervals are derived from the estimate of equation (3) including all controls (balanced covariates, island fixed effects, and their interactions with risk-aversion). $\mathrm{N}=476$. 


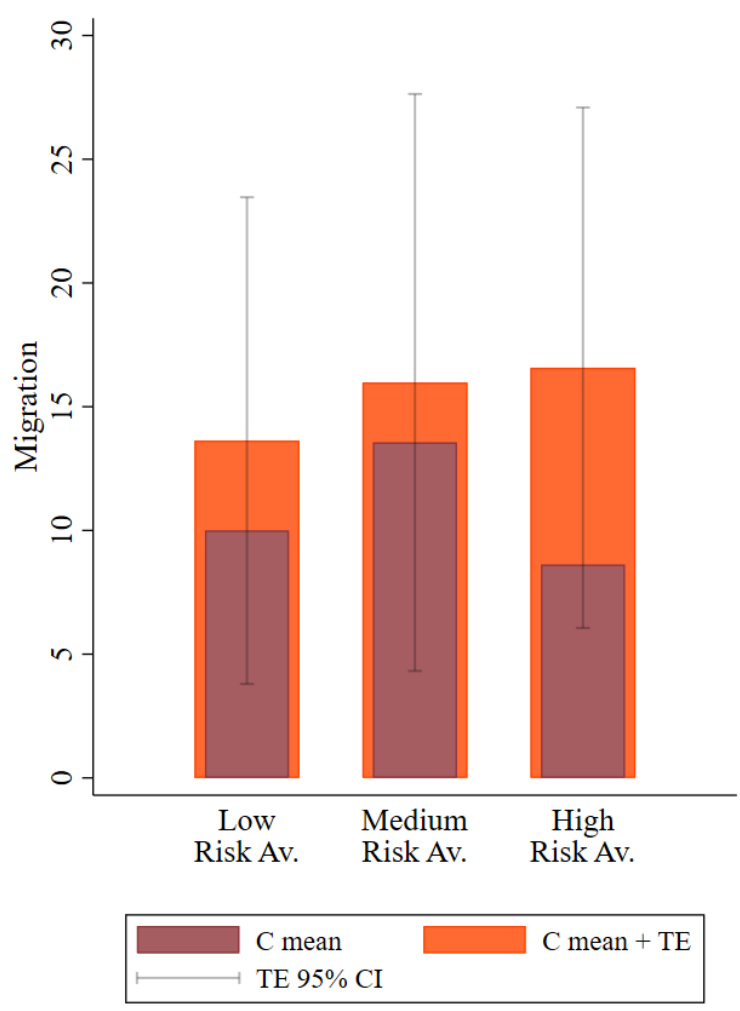

Figure A7: Risk-aversion channel - three groups

Notes: This figure shows follow-up household migration rates conditional on baseline risk-aversion. Households are divided in three groups of equal size. Treatment effects and $95 \%$ confidence intervals are derived from the estimate of equation (3) including all controls (balanced covariates, island fixed effects, and their interactions with risk-aversion). $\mathrm{N}=476$. 


\section{B Theoretical Model}

We study the decision process of a household that can send one of its member abroad to work. The model has two periods, denoted $t_{1}$ and $t_{2}$. In both periods, the household first decides whether to finance the migration of one its member. If the member migrates, the household needs to pay the upfront migration costs $c$ using savings $s_{t-1}$ (a credit market will be added in Section B.3). Then, the household earns an income, which is denoted $w_{o}$ if all members are living in the origin country, and $w_{d}$ if one member has migrated to the destination country. We assume that migration increases household income $\left(w_{d}>w_{o}\right)$. Migration is therefore seen as an investment. Finally, the household decides how much of the income and savings to consume and to save for the next period. Household savings are denoted $s_{t}\left(s_{t} \geq 0\right)$. Without loss of generality, we assume that the household stays if it is indifferent between staying or migrating.

We abstract from the decision to smooth consumption over time by assuming that the utility function of the household is a function of lifetime wealth $\left(u^{\prime}>0, u^{\prime \prime} \leq 0\right)$. Without this assumption, there is no closed-form solution when risk is included in the model. To simplify the model, we assume that the gains from migration are only monetary. Similar results are obtained if $w_{d}$ includes both the monetary and nonmonetary benefits of migration (e.g. access to better healthcare, family reunification).

The household has to compare three options: investing in migration in $t_{1}$ (Case 1 ), investing in migration in $t_{2}$ (Case 2), or not investing in migration (Case 3 ). The lifetime utilities associated with these cases are:

$$
\begin{aligned}
& U^{\text {Case } 1}=u\left(s_{0}-c+2 w_{d}\right) \\
& U^{\text {Case2 }}=u\left(s_{0}-c+w_{0}+w_{d}\right) \\
& U^{\text {Case3 }}=u\left(s_{0}+2 w_{0}\right)
\end{aligned}
$$

The following proposition characterizes the decision to finance the migration of a household member.

Proposition 1. A household member migrates in $t_{1}$ if and only if migration can be financed in $t_{1}$ and if the benefit of migrating in $t_{1}$ is larger than the cost:

$$
\left\{\begin{array}{l}
s_{0} \geq c . \\
2\left(w_{d}-w_{o}\right)>c
\end{array}\right.
$$

A household member migrates in $t_{2}$ if and only if migration can be financed in $t_{2}$ but not in $t_{1}$ and if the benefit of migrating in $t_{2}$ is larger than the cost: 


$$
\left\{\begin{array}{l}
c-w_{o} \leq s_{0}<c . \\
w_{d}-w_{o}>c
\end{array}\right.
$$

Proof. The lifetime utilities of financing migration in $t_{1}$ (Case 1 ), financing migration in $t_{2}$ (Case 2), or not migrating at all (Case 3) are:

$$
\begin{aligned}
& U^{\text {Case } 1}=u\left(s_{0}-c+2 w_{d}\right) \\
& U^{\text {Case2 }}=u\left(s_{0}-c+w_{0}+w_{d}\right) \\
& U^{\text {Case3 }}=u\left(s_{0}+2 w_{0}\right)
\end{aligned}
$$

Case 1: migration in $t_{1}$ Financing migration in $t_{1}$ is only feasible if the initial level of savings $s_{0}$ is large enough to finance the upfront cost of migration $\left(s_{0} \geq c\right)$. If feasible, a household member migrates in $t_{1}$ if:

$$
\left\{\begin{array}{l}
U^{\text {Case } 1}>U^{\text {Case } 2} \Leftrightarrow w_{d}-w_{o}>0 \\
U^{\text {Case } 1}>U^{\text {Case3 }} \Leftrightarrow 2\left(w_{d}-w_{0}\right)>c
\end{array}\right.
$$

Case 2: migration in $t_{2}$ Financing migration in $t_{2}$ is only feasible if the household can save enough in $t_{1}$ to pay the upfront cost of migration in $t_{2}\left(s_{0}+w_{0}>c\right)$. If $s_{0} \geq c$, migrating in $t_{1}$ is always preferable to migrating in $t_{2}$. If $c-w_{0} \leq s_{0}<c$, a household member migrates in $t_{2}$ if:

$$
U^{\text {Case } 2}>U^{\text {Case3 }} \Leftrightarrow w_{d}-w_{o}>c
$$

The possible outcomes are represented in Figure A8 as a function of the wage differential $w_{d}-w_{o}$ and of initial savings $s_{0}$. In words, a member migrates in $t_{1}$ if savings are large and if the return to migration is intermediate or large. A member migrates in $t_{2}$ if savings are intermediate and if the return to migration is large.

In the next sections, we study how a cash transfer can affect this decision-making process, distinguishing four scenarios: an unconditional cash transfer (Section B.1), a cash transfer conditional on not migrating (Section B.2), an unconditional cash transfer with a functioning credit market (Section B.3), and an unconditional cash transfer in the presence of risk and risk aversion (Section B.4). 


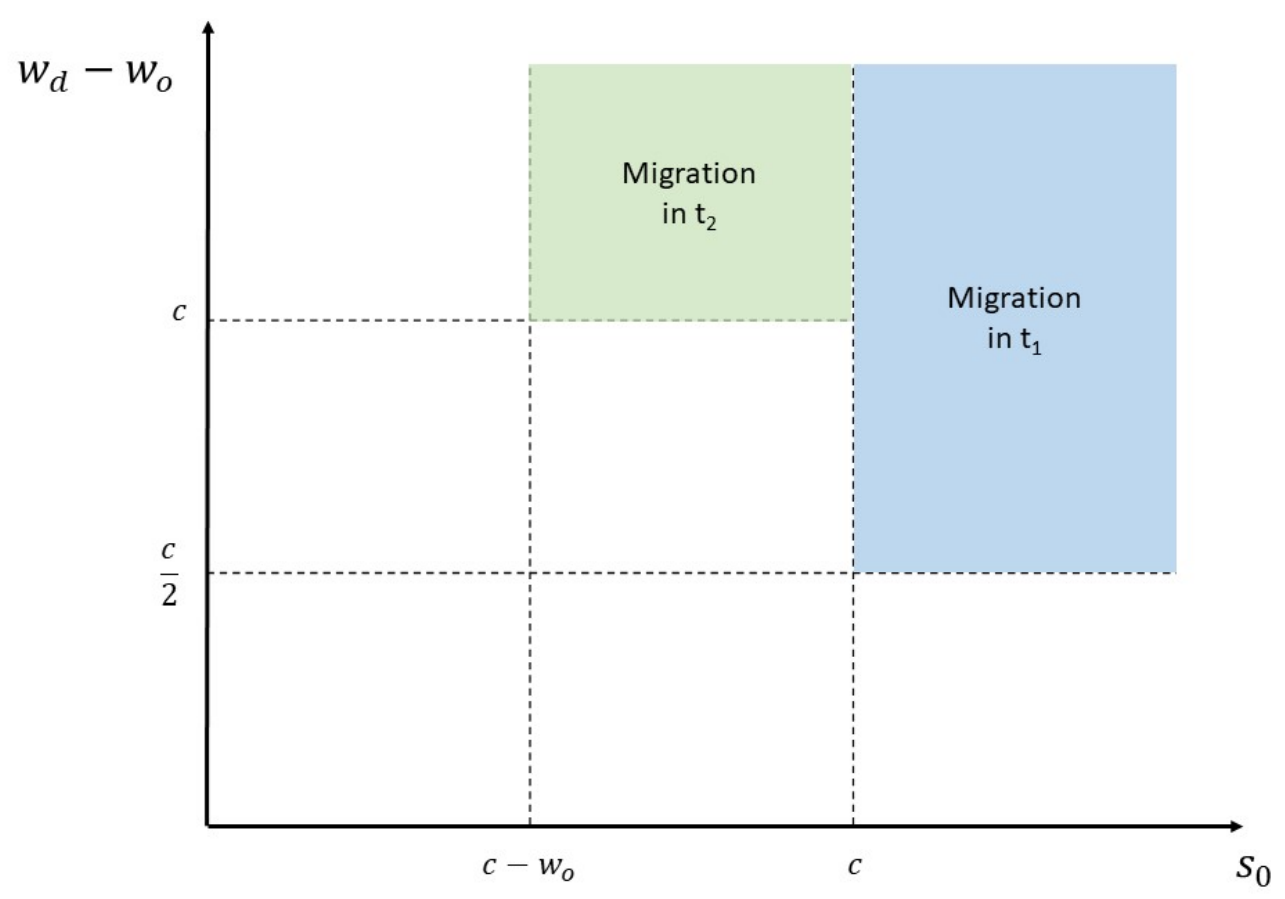

Figure A8: Outcomes of the benchmark model as a function of the wage differential $w_{d}-w_{o}$ and of initial savings $s_{0}$

\section{B.1 The liquidity channel}

In this first extension of the benchmark model, we assume that the household is selected to receive an unconditional cash transfer $\tau>0$ at the end of $t_{1}$. This extra wealth can be consumed or saved. While the utility returns from migration are not affected by the cash transfer, as the cash transfer is unconditional, the budget constraint (6) is eased by the cash transfer. The cash transfer modifies the decision to migrate as follows.

Proposition 2. While the unconditional cash transfer does not affect decision to migrate in $t_{1}$, it facilitates migration in $t_{2}$ by easing the budget constraint. In particular, a household member migrates in $t_{2}$ if:

$$
\left\{\begin{array}{l}
c-w_{o}-\tau \leq s_{0}<c . \\
w_{d}-w_{o}>c
\end{array}\right.
$$

Proof. The lifetime utilities of financing migration in $t_{1}$ (Case 1 ), financing migration in $t_{2}$ (Case 2), or not migrating at all (Case 3) are: 


$$
\begin{aligned}
& U^{\text {Case } 1}=u\left(s_{0}-c+2 w_{d}+\tau\right) \\
& U^{\text {Case2 }}=u\left(s_{0}-c+w_{0}+w_{d}+\tau\right) \\
& U^{\text {Case3 }}=u\left(s_{0}+2 w_{0}+\tau\right)
\end{aligned}
$$

Case 1: migration in $t_{1}$ Financing migration in $t_{1}$ is only feasible if the initial level of savings $s_{0}$ is large enough to finance the upfront cost of migration $\left(s_{0} \geq c\right)$. This budget constraint is not affected by the unconditional cash transfer, as it is received after the decision to migrate in $t_{1}$. If feasible, a household member migrates in $t_{1}$ if:

$$
\left\{\begin{array}{l}
U^{\text {Case } 1}>U^{\text {Case } 2} \Leftrightarrow w_{d}-w_{o}>0 \\
U^{\text {Case } 1}>U^{\text {Case3 }} \Leftrightarrow 2\left(w_{d}-w_{o}\right)>c
\end{array}\right.
$$

Case 2: migration in $t_{2}$ Financing migration in $t_{2}$ is only feasible if the household can save enough in $t_{1}$ to pay the upfront cost of migration in $t_{2}\left(s_{0}+w_{0}+\tau>c\right)$. If $s_{0} \geq c$, migrating in $t_{1}$ is always preferable to migrating in $t_{2}$. If $c-w_{0}-\tau \leq s_{0}<c$, a household member migrates in $t_{2}$ if:

$$
U^{\text {Case2 }}>U^{\text {Case3 }} \Leftrightarrow w_{d}-w_{o}>c
$$

It is clear that inequality (6) is more stringent that inequality (8): the amount $\tau$ eases the budget constraint of the household in $t_{2}$, as illustrated in Figure A9. The cash transfer allows the migration of households that would be liquidity constrained without the transfer but that are able to finance migration in $t_{2}$ thanks to the transfer.

\section{B.2 Opportunity cost channel}

We examine the effect of adding a conditionality to the cash transfer. If the cash transfer is conditional on all household members working in the origin country at $t_{1}$, households that would have been migrating in $t_{1}$ without the conditionality cancel or postpone migration if the value of the cash transfer is larger than the cost of canceling or delaying migration. Compared to the benchmark model, the conditional cash transfer does not affect the lifetime utility of migrating in $t_{1}$, but it increases the lifetime utility of migrating in $t_{2}$ and the lifetime utility of not migrating at all.

The following proposition describes when the household finances the migration of one of its member in the presence of a conditional cash transfer. 


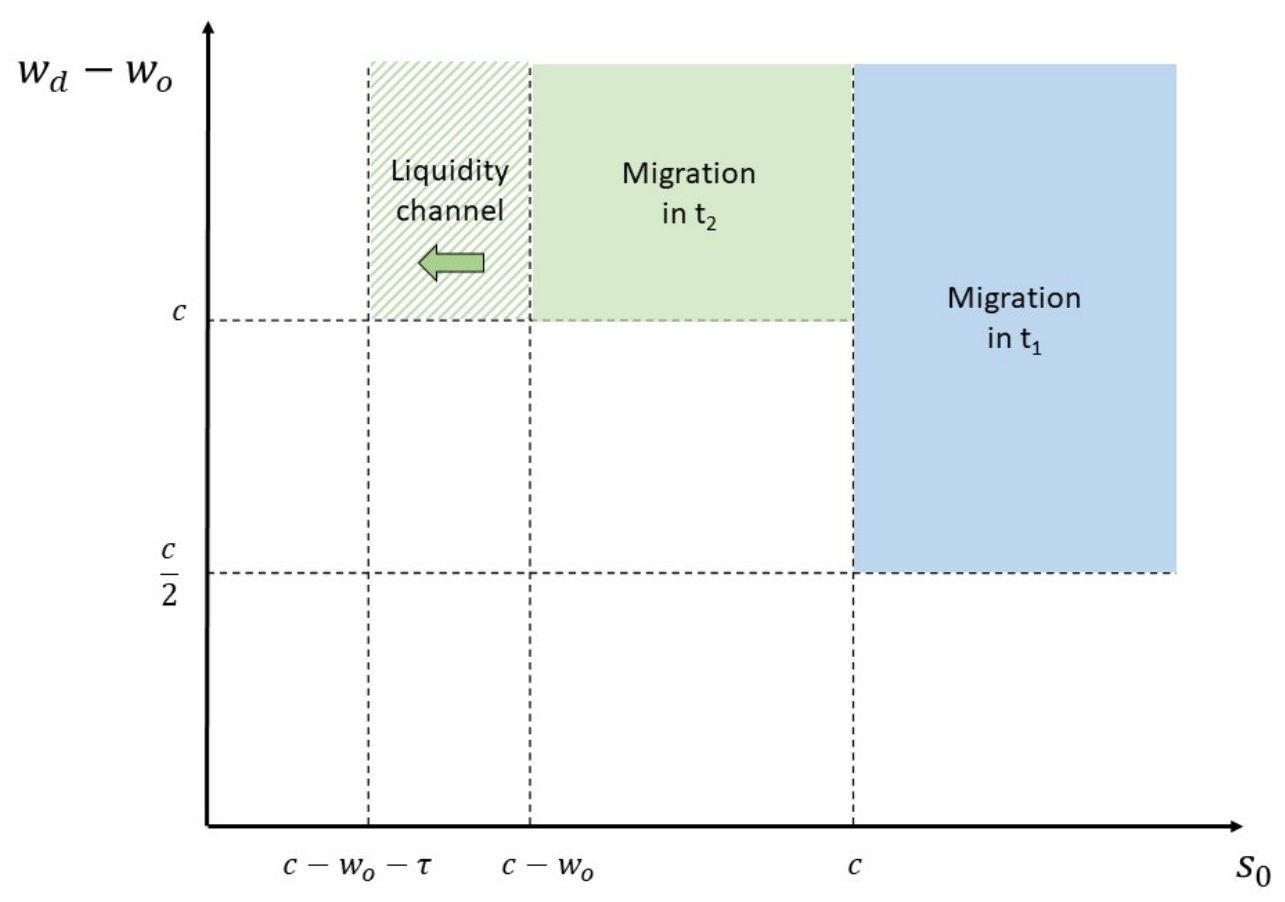

Figure A9: Effect of a cash transfer through the liquidity channel

Proposition 3. In the presence of a conditional cash transfer, a household member migrates in $t_{1}$ if and only if:

$$
\left\{\begin{array}{l}
s_{0}>c . \\
w_{d}-w_{o}>\operatorname{Max}\left(\frac{c+\tau}{2}, \tau\right)
\end{array}\right.
$$

A household member migrates in $t_{2}$ if conditions (8) and (9) are satisfied, or if:

$$
\left\{\begin{array}{l}
s_{0}>c \\
c<\left(w_{d}-w_{o}\right)<\tau
\end{array}\right.
$$

Proof. The lifetime utilities of financing migration in $t_{1}$ (Case 1), financing migration in $t_{2}$ (Case 2), or not migrating at all (Case 3) are:

$$
\begin{aligned}
& U^{\text {Case } 1}=u\left(s_{0}-c+2 w_{d}\right) \\
& U^{\text {Case } 2}=u\left(s_{0}-c+w_{0}+w_{d}+\tau\right) \\
& U^{\text {Case3 }}=u\left(s_{0}+2 w_{0}+\tau\right)
\end{aligned}
$$

Case 1: migration in $t_{1}$ Financing migration in $t_{1}$ is only feasible if the initial level of savings $s_{0}$ is large enough to finance the upfront cost of migration $\left(s_{0} \geq c\right)$. This budget constraint is not affected by the conditional cash transfer. If feasible, a household 
member migrates in $t_{1}$ if:

$$
\left\{\begin{array}{l}
U^{\text {Case } 1}>U^{\text {Case } 2} \Leftrightarrow w_{d}-w_{o}>\tau \\
U^{\text {Case } 1}>U^{\text {Case } 3} \Leftrightarrow 2\left(w_{d}-w_{o}\right)>c+\tau
\end{array}\right.
$$

If $\tau>c$, then the first condition is more stringent than the second one $\left(U^{\text {Case } 2}>\right.$ $\left.U^{\text {Case } 3}\right)$. If $\tau<c$, then the second condition is more stringent than the first one $\left(U^{\text {Case2 }}<U^{\text {Case3 }}\right)$

Case 2: migration in $t_{2}$ Financing migration in $t_{2}$ is only feasible if the household can save enough in $t_{1}$ to pay the upfront cost of migration in $t_{2}\left(s_{0}+w_{0}+\tau>c\right)$. If $c-w_{0} \leq s_{0}<c$, migration cannot be financed in $t_{1}$. In this case, a household member migrates in $t_{2}$ if:

$$
U^{\text {Case2 }}>U^{\text {Case3 }} \Leftrightarrow w_{d}-w_{o}>c
$$

If $s_{0} \geq c$, migration can be financed in both $t_{1}$ and $t_{2}$. In this case, a household member migrates in $t_{2}$ if:

$$
\left\{\begin{array}{l}
U^{\text {Case } 2} \geq U^{\text {Case } 1} \Leftrightarrow w_{d}-w_{o} \leq \tau \\
U^{\text {Case } 2}>U^{\text {Case3 }} \Leftrightarrow w_{d}-w_{o}>c
\end{array}\right.
$$

The effect of the conditional cash transfer is illustrated in Figures 10(a) and 10(b). On the one hand, the cash transfer increases households' ability to finance migration in $t_{2}$ (liquidity effect). On the other hand, the conditionality increases the opportunity cost of migrating in $t_{1}$. It affects the decision of households able to finance migration at $t_{1}\left(s_{0}>c\right)$ and for which the wage differential $w_{d}-w_{0}$ is lower than the transfer $\tau$. These households are either prevented from migrating (if the wage differential is low such that migration in $t_{2}$ is not optimal) or they postpone migration until $t_{2}$ (if the wage differential is larger than the upfront cost of migration).

\section{B.3 Collateral channel}

So far, we have assumed that credit markets are absent. The presence of an effective credit market would ease the budget constraint of households, who can borrow to finance migration in $t_{1}$ and pay back the loan in $t_{2}$ thanks to the wage differential $w_{d}-w_{o}$. We assume that households can borrow a maximum amount $B \geq 0$ at the beginning of $t_{1} \sqrt{36}$ The loan needs to be repaid at the end of $t_{2}$ with an interest rate $r$.

\footnotetext{
${ }^{36}$ In practice, the amount $B$ is determined by the lender. $B$ is expected to depend on expected future income, including anticipated gains from migration if the lender believes the household is likely to
} 


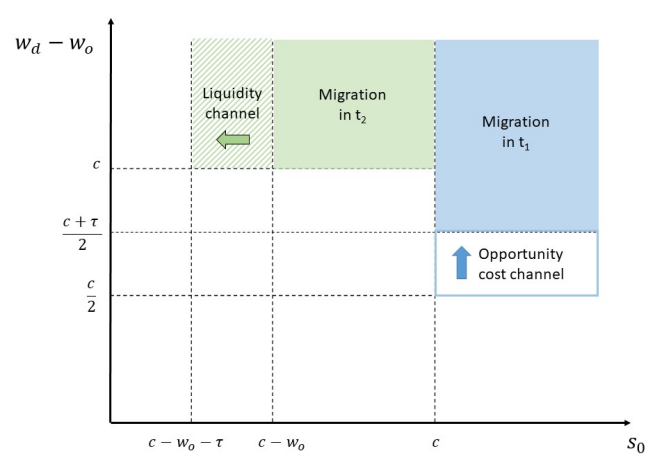

(a) Small cash transfer $\tau<c$

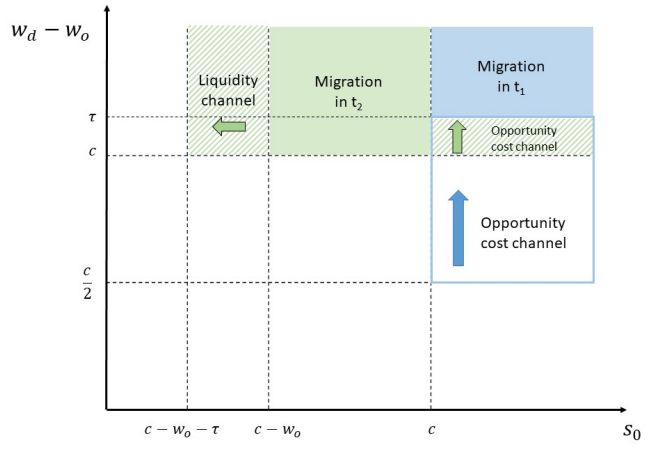

(b) Large cash transfer $\tau>c$

Figure A10: Effect of a conditionality

In the presence of such credit market (and in the absence of cash transfer), a liquidityconstrained household borrows in $t_{1}$ to finance the migration of one of its member in $t_{1}$ if the following conditions are jointly satisfied.

Proposition 4. The household borrow to finance migration in $t_{1}$ if:

$$
\left\{\begin{array}{l}
c-B \leq s_{0}<c . \\
w_{d}-w_{o}>\operatorname{Max}\left(r\left(c-s_{0}\right), \frac{c+r\left(c-s_{0}\right)}{2}\right)
\end{array}\right.
$$

Proof. If $s_{0} \geq c$, the household does not need to borrow to finance migration in $t_{1}$. Therefore, borrowing only occurs if borrowing is necessary and sufficient to finance migration in $t_{1}$, which occurs if $c-B \leq s_{0}<c$. If the household borrow, it will borrow the amount $c-s_{0}$, which is the minimum loan that allows financing migration in $t_{1}$. The household will not borrow more as borrowing is costly ( $r \geq 0$ and as consumption smoothing is irrelevant following the assumption that households are maximizing lifetime wealth.

The lifetime utilities of financing migration in $t_{1}$ with savings (Case $1 \mathrm{~A}$ ), financing migration in $t_{1}$ with a loan (Case $1 \mathrm{~B}$ ), financing migration in $t_{2}$ (Case 2), or not migrating at all (Case 3) are:

$$
\begin{aligned}
U^{\text {Case } 1 A} & =u\left(s_{0}-c+2 w_{d}\right) \\
U^{\text {Case } 1 B} & =u\left(s_{0}-c+2 w_{d}-\left(c-s_{0}\right) r\right)= \\
U^{\text {Case } 2} & =u\left(s_{0}-c+w_{0}+w_{d}\right) \\
U^{\text {Case } 3} & =u\left(s_{0}+2 w_{0}\right)
\end{aligned}
$$

invest in migration. 
If borrowing is necessary and sufficient to finance migration in $t_{1}\left(c-B \leq s_{0}<c\right)$, borrowing is optimal if:

$$
\left\{\begin{array}{l}
U^{\text {Case } 1 B}>U^{\text {Case2 }} \Leftrightarrow w_{d}-w_{o}>r\left(c-s_{0}\right) \\
U^{\text {Case } 1 B}>U^{\text {Case3 }} \Leftrightarrow 2\left(w_{d}-w_{o}\right)>c+r\left(c-s_{0}\right)
\end{array}\right.
$$

Thanks to the credit market, a household facing a liquidity constraint in $t_{1}$ can finance migration through borrowing if the maximum amount of the loan $B$ and initial savings $s_{0}$ are large enough to cover the upfront cost of migration $c$ (Figure 11(a)) 37 However, because borrowing is costly, inequality (15), which is represented by the yellow lines on Figure 11(a), is more stringent that inequality (9).

With a functioning credit market, an unconditional cash transfer has three effects on the decision to finance migration, as illustrated in Figure 11(b). In line with the liquidity channel described in Section B.1, the direct effect of an unconditional cash transfer is to ease the budget constraint in $t_{2}$, which facilitates migration in $t_{2}$ for households with intermediate levels of savings $\left(c-w_{0}-\tau \leq s_{0} \leq c-w_{o}\right)$. But in the presence of a functioning credit market, a cash transfer can have two other indirect effects. First, the maximum amount that households can borrow, $B$, is likely to increase as soon as households are selected to benefit from the unconditional cash transfer, as the guaranteed future income stream can play the role of a collateral. If cash transfers are administered by a micro-credit organization, $B$ is also likely to increase as a consequence of the greater proximity between beneficiaries and the micro-credit organization. If the maximum amount of the loan, $B$, is increased, more households are able to finance migration in $t_{1}$ through borrowing. Second, the interest rate of the loan $r$ is likely to be reduced because the risk of default is reduced by the increase in future income, which plays the role of a collateral. If the interest rate $r$ is reduced, more households find it optimal to borrow to finance migration in $t_{1}$.

\section{B.4 Risk-aversion channel}

In this section, we modify the benchmark model and assume that migration is risky. With a probability $p \in] 0,1[$, the migrant reaches its destination and the household income is $w_{d}$. With a probability $1-p$, the migrant's journey is unsuccessful, and the household income is $w_{0}$. In the presence of risk, the degree of risk aversion of the household will influence the decision-making process. Risk aversion means that the

\footnotetext{
${ }^{37}$ In Figure 11(a) we assume that $B<w_{0}$. It is indeed very unlikely that a lender would provide loans that are larger than the net present value of future income in the origin country, $\frac{w_{o}}{1+r}$. Results are qualitatively similar if $B \geq w_{0}$ : instead of self-financing migration in $t_{2}$, households with $c-B \leq s_{0}<c$ borrow to finance migration in $t_{1}$.
} 


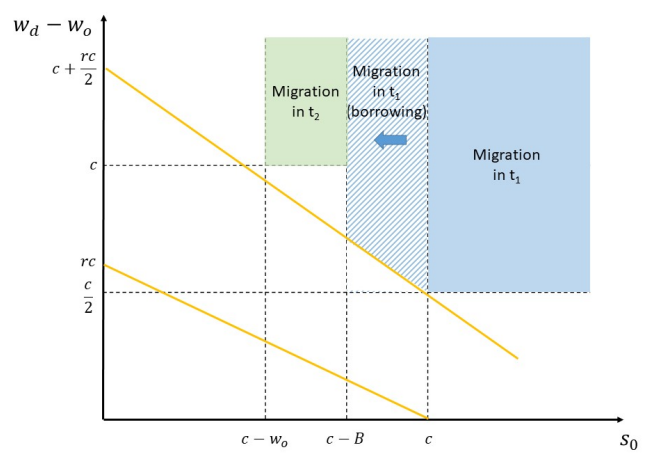

(a) Without cash transfer

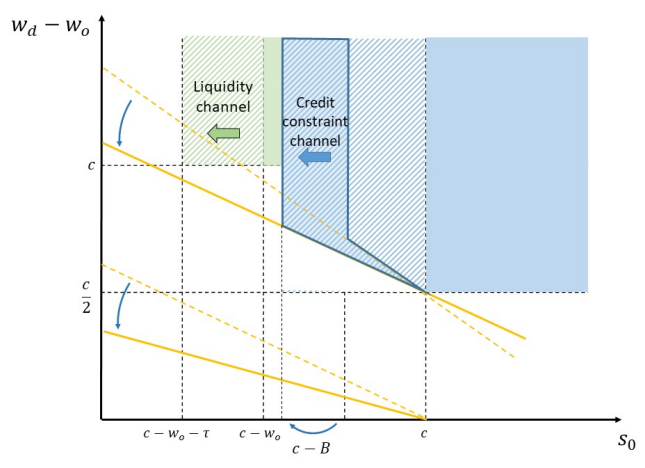

(b) With a cash transfer $\tau$

Figure A11: Decision to finance migration using credit

utility function is concave $\left(u^{\prime \prime}<0\right)$, which implies that households dislike zero-mean risks.

We introduce risk aversion in the model using the concepts of certainty equivalent and risk premium (Eeckhoudt et al., 2005; Myerson, 2005). The certainty equivalent of a gamble for a decision-maker is the sure amount of money that the decision-maker would be willing to accept instead of the gamble. The difference between the expected monetary value of the gamble and the certainty equivalent of the gamble is called the risk premium 38 In the presence of risk and risk aversion, the household finances the migration attempt of one of its members if the following conditions are satisfied.

Proposition 5. If migration is risky, a household member attempts to migrate in $t_{1}$ if:

$$
\left\{\begin{array}{l}
s_{0}>c . \\
2 p\left(w_{d}-w_{0}\right)>c+\pi_{1}
\end{array}\right.
$$

where $\pi_{1}$ is the risk premium associated with financing migration in $t_{1} \cdot 39$

A household member attempts to migrate in $t_{2}$ if:

$$
\left\{\begin{array}{l}
c-w_{0}<s_{0}<c . \\
p\left(w_{d}-w_{o}\right)>c+\pi_{2}
\end{array}\right.
$$

where $\pi_{2}$ is the risk premium associated with financing migration in $t_{2} \cdot 40$

\footnotetext{
${ }^{38}$ For a small risk, the risk premium $\pi$ can be approximated as: $\pi \approx 1 / 2 \sigma^{2} A(w)$ where $\sigma$ is the variance of the gamble, and $A(w)=-u^{\prime \prime} / u^{\prime}$ is the degree of absolute risk aversion of the decisionmaker, which is a function of wealth $w$. For a large risk, the risk premium also depends upon the other moments of the distribution of the risk, not just its mean and variance.

${ }^{39}$ The risk premium $\pi_{1}$ is defined as: $u\left(s_{o}-c+2 p w_{d}+2(1-p) w_{o}-\pi_{1}\right)=p\left[u\left(s_{0}-c+2 w_{d}\right)\right]+$ $(1-p)\left[u\left(s_{0}-c+2 w_{o}\right)\right]$.

${ }^{40}$ The risk premium $\pi_{2}$ is defined as: $u\left(s_{0}-c+w_{o}+p w_{d}+(1-p) w_{o}-\pi_{2}\right)=p\left[u\left(s_{0}-c+w_{o}+\right.\right.$ $\left.\left.w_{d}\right)\right]+(1-p)\left[u\left(s_{0}-c+2 w_{o}\right)\right]$.
} 
Proof. The lifetime expected utility of a household attempting to migrate in $t_{1}$ is:

$$
\begin{aligned}
U^{\text {Case } 1} & =p\left[u\left(s_{0}-c+2 w_{d}\right)\right]+(1-p)\left[u\left(s_{0}-c+2 w_{o}\right)\right] \\
& =u\left(s_{o}-c+2 p w_{d}+2(1-p) w_{o}-\pi_{1}\right)
\end{aligned}
$$

where $\pi_{1}$ is the risk premium associated with migrating in $t_{1}$. The lifetime expected utility of a household attempting to migrate in $t_{2}$ is:

$$
\begin{aligned}
U^{\text {Case } 2} & =p\left[u\left(s_{0}-c+w_{o}+w_{d}\right)\right]+(1-p)\left[u\left(s_{0}-c+2 w_{o}\right)\right] \\
& =u\left(s_{o}-c+w_{o}+p w_{d}+(1-p) w_{o}-\pi_{2}\right)
\end{aligned}
$$

where $\pi_{2}$ is the risk premium associated with migrating in $t_{2}$. The lifetime utility of a household who does not finance migration is:

$$
U^{\text {Case3 }}=u\left(s_{0}+2 w_{0}\right)
$$

Case 1: migration in $t_{1}$ Financing migration in $t_{1}$ is only feasible if the initial level of savings $s_{0}$ is large enough to finance the upfront cost of migration $\left(s_{0} \geq c\right)$. It is

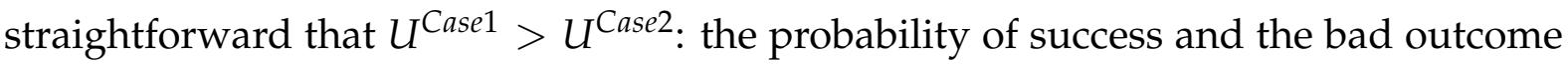
are the same for these two lotteries, while the good outcome is better in Case 1 (given the assumption $\left.u^{\prime}>0\right)$. Therefore, if feasible $\left(s_{0} \geq c\right)$, a household member migrates in $t_{1}$ if:

$$
U^{\text {Case1 }}>U^{\text {Case3 }} \Leftrightarrow 2 p(w d-w o)>c+\pi_{1}
$$

Case 2: migration in $t_{2}$ Financing migration in $t_{2}$ is only feasible if the initial level of savings $s_{0}$ and the wage at origin are large enough to finance the upfront cost of migration in $t_{2}\left(s_{0}+w_{0} \geq c\right)$. If $s_{0} \geq c$, migration in $t_{2}$ is never optimal as $U^{\text {Case } 1}>$ $U^{\text {Case2 }}$. If $c-w_{0} \leq s_{0}<c$, a household member migrates in $t_{2}$ if:

$$
U^{\text {Case2 }}>U^{\text {Case3 }} \Leftrightarrow p(w d-w o)>c+\pi_{2}
$$

The presence of risk has two effects, which are illustrated in Figure 12(a). First, risk reduces the expected benefit from migration by a factor $p$. Second, risk aversion 
reduces households' expected utility of migrating, as captured by the risk premiums $\pi_{1}$ and $\pi_{2}$.

In the presence of risk and risk aversion, a cash transfer not only impacts the budget constraint (liquidity channel), but also the expected utility returns from migration. The cash transfer is an income shock. Therefore, the direction of the impact depends on how risk aversion varies with income, as summarized in the following proposition.

Proposition 6. An unconditional cash transfer eases the budget constraint in $t_{2}$ (liquidity channel). Furthermore, if the utility function of the household is characterized by decreasing absolute risk aversion (DARA), the unconditional cash transfer increases the expected utility returns from investing in migration. By contrast, if the utility function is characterized by increasing absolute risk aversion (IARA), the unconditional cash transfer reduces the expected utility returns from investing in migration.

Proof. The lifetime expected utility of a household attempting to migrate at the beginning of $t_{1}$ and benefiting from an unconditional cash transfer at the end of $t_{1}$ is:

$$
\begin{aligned}
U^{\text {Case } 1} & =p\left[u\left(s_{0}-c+2 w_{d}+\tau\right)\right]+(1-p)\left[u\left(s_{0}-c+2 w_{o}+\tau\right)\right] \\
& =u\left(s_{o}-c+2 p w_{d}+2(1-p) w_{o}+\tau-\pi_{1}^{\prime}\right)
\end{aligned}
$$

where $\pi_{1}^{\prime}$ is the risk premium associated with migrating in $t_{1}$. The lifetime expected utility of a household benefiting from an unconditional cash transfer at the end of $t_{1}$ and attempting to migrate at the beginning of $t_{2}$ is:

$$
\begin{aligned}
U^{\text {Case } 2} & =p\left[u\left(s_{0}-c+w_{0}+w_{d}+\tau\right)\right]+(1-p)\left[u\left(s_{0}-c+2 w_{0}+\tau\right)\right] \\
& =u\left(s_{0}-c+w_{o}+p w_{d}+(1-p) w_{o}+\tau-\pi_{2}^{\prime}\right)
\end{aligned}
$$

where $\pi_{2}^{\prime}$ is the risk premium associated with migrating in $t_{2}$. The lifetime utility of a household benefiting from an unconditional cash transfer at the end of $t_{1}$ and not attempting to migrate is:

$$
U^{\text {Case3 }}=u\left(s_{0}+2 w_{0}+\tau\right)
$$

Case 1: migration in $t_{1}$ Financing migration in $t_{1}$ is only feasible if the initial level of savings $s_{0}$ is large enough to finance the upfront cost of migration $\left(s_{0} \geq c\right)$. It is straightforward that $U^{\text {Case1 }}>U^{\text {Case2 }}$ : the probability of success and the bad outcome are the same for these two lotteries, while the good outcome is better in Case 1 (given 
the assumption $\left.u^{\prime}>0\right)$. Therefore, if feasible $\left(s_{0} \geq c\right)$, a household member migrates in $t_{1}$ if:

$$
U^{\text {Case } 1}>U^{\text {Case3 }} \Leftrightarrow 2 p(w d-w o)>c+\pi_{1}^{\prime}
$$

Case 2: migration in $t_{2}$ Financing migration in $t_{2}$ is only feasible if the sum of the initial level of savings $s_{0}$, the wage at origin $w_{0}$ and the cash tranfer $\tau$ is large enough to finance the upfront cost of migration in $t_{2}\left(s_{0}+w_{0}+\tau \geq c\right)$. If $s_{0} \geq c$, migration in $t_{2}$ is never optimal because $U^{\text {Case } 1}>U^{\text {Case2 }}$. If $c-w_{0}-\tau \leq s_{0}<c$, a household member migrates in $t_{2}$ if:

$$
U^{\text {Case2 }}>U^{\text {Case3 }} \Leftrightarrow p(w d-w o)>c+\pi_{2}^{\prime}
$$

The budget constraint in $t_{2}$ is eased by the cash transfer (liquidity channel). Furthermore, if the utility function is characterized by decreasing absolute risk aversion (DARA), $\pi_{1}^{\prime}<\pi_{1}$ and $\pi_{2}^{\prime}<\pi_{2}$, implying that households are less risk averse thanks to the transfer and more willing to accept the risk associated with migration. By contrast, if the utility function is characterized by increasing absolute risk aversion (IARA), $\pi_{1}^{\prime}>\pi_{1}$ and $\pi_{2}^{\prime}>\pi_{2}$, implying that households become more risk averse with the cash transfer and less willing to accept the risk of migrating. If the household is risk neutral, $\pi_{1}^{\prime}=\pi_{1}$ and the only effect of the cash transfer is through the liquidity channel.

Experimental and empirical evidence supports the hypothesis of decreasing absolute risk aversion. ${ }^{41}$ In Figure 12(b), we illustrate the effect of the cash transfer when the utility function is DARA. The direct effect of the transfer is to ease the budget constraint of the household in $t_{2}$ (liquidity channel). But if migration is risky and if the utility function is DARA, the cash transfer also reduces risk aversion, thereby increasing the expected utility returns from financing migration in $t_{1}$ or in $t_{2}$.

In this section, we have focused exclusively on the monetary risks of migration in order to simplify the framework. Considering the additional risk of dying en route would not change the main conclusion of this section. The risk of dying would lead to the addition of a negative term on the left-hand side of conditions (17) and (19). Our main result - Proposition 6- would not be affected.

\footnotetext{
${ }^{41}$ See e.g. Dohmen et al. (2011), Dohmen et al. (2010), Yesuf and Bluffstone (2009), Guiso and Paiella (2008), Wik et al. (2004), and Levy (1994).
} 


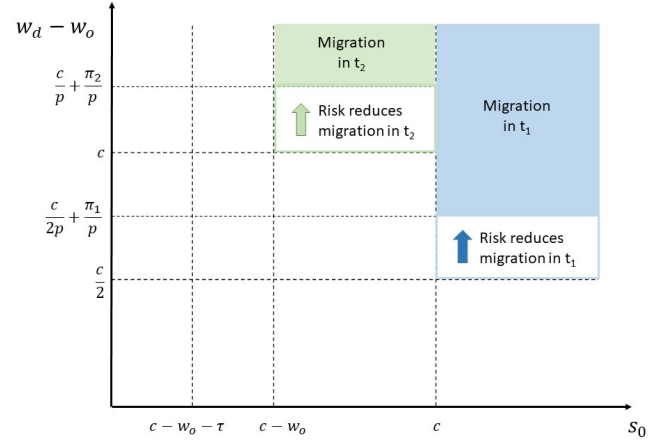

(a) Effect of risk on the decision to migrate

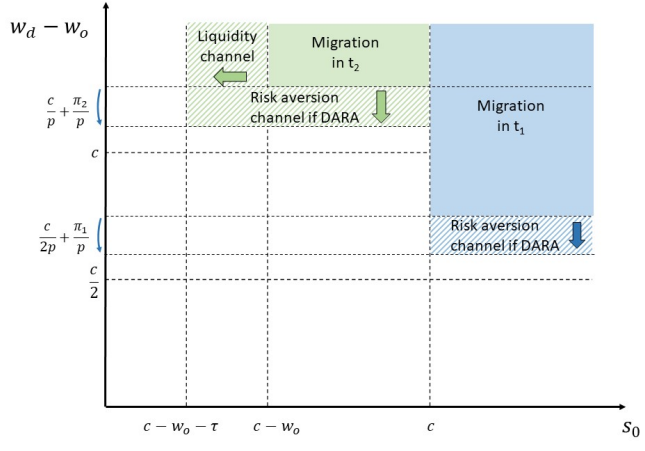

(b) Effect of an unconditional cash transfer with DARA

Figure A12: Decision to migrate if migration is risky

\section{B.5 References}

Dohmen, T., Falk, A., Huffman, D., and Sunde, U. (2010). Are risk aversion and impatience related to cognitive ability? American Economic Review, 100(3):1238-60.

Dohmen, T., Falk, A., Huffman, D., Sunde, U., Schupp, J., andWagner, G. G. (2011). Individual risk attitudes: Measurement, determinants, and behavioral consequences. Journal of the European Economic Association, 9(3):522-550.

Eeckhoudt, L., Gollier, C., and Schlesinger, H. (2005). Economic and financial decisions under risk. Princeton University Press.

Guiso, L. and Paiella, M. (2008). Risk aversion, wealth, and background risk. Journal of the European Economic association, 6(6):1109-1150.

Levy, H. (1994). Absolute and relative risk aversion: An experimental study. Journal of Risk and uncertainty, 8(3):289-307.

Myerson, R. B. (2005). Probability models for economic decisions. Duxbury Press, Pacific Grove, CA.

Wik, M., Aragie Kebede, T., Bergland, O., and Holden, S. T. (2004). On the measurement of risk aversion from experimental data. Applied Economics, 36(21):2443-2451.

\section{Sub-analysis outlined in the pre-analysis plan}

Migration reasons When respondents reported a migrant, we further inquired about the reason for migrating. The impact of the program by migration reason is presented in Table A12. Respondents declared three main reasons for migrating: economic reasons, health reasons, and family reasons. The overall positive effect on migration we observe seems to be especially driven by individuals migrating for health reasons, followed by family migration, and economic migration. However, Table A13 shows that 
economic migrants are not the only group to send remittances to their household of origin. People migrating for health and family reasons also remit. This suggests that the different migration reasons are not mutually exclusive, even though our survey instruments inquired respondents to select only one type of migration. In addition, people migrating for economic opportunities might state health or family motives because they believe these motives could be seen as more legitimate.

Table A12: Treatment effects by migration reasons

\begin{tabular}{|c|c|c|c|c|c|c|}
\hline & \multicolumn{6}{|c|}{$\begin{array}{c}\text { Migration } \\
\text { (excl. returns) }\end{array}$} \\
\hline & (1) & $(2)$ & (3) & (4) & (5) & $(6)$ \\
\hline & Economic & Health & Family & Studies & Tourism & Other \\
\hline \multirow[t]{2}{*}{ Treatment } & 0.007 & $0.020^{* * *}$ & 0.011 & -0.001 & -0.004 & -0.001 \\
\hline & $(0.007)$ & $(0.007)$ & $(0.007)$ & $(0.004)$ & $(0.003)$ & $(0.002)$ \\
\hline Extended controls & Yes & Yes & Yes & Yes & Yes & Yes \\
\hline Island FE & Yes & Yes & Yes & Yes & Yes & Yes \\
\hline Control mean & 0.023 & 0.025 & 0.026 & 0.007 & 0.005 & 0.002 \\
\hline \multirow[t]{4}{*}{ Observations } & 2163 & 2163 & 2163 & 2163 & 2163 & 2163 \\
\hline & \multicolumn{6}{|c|}{$\begin{array}{c}\text { Migration } \\
\text { (incl. returns) }\end{array}$} \\
\hline & (1) & (2) & (3) & (4) & (5) & $(6)$ \\
\hline & Economic & Health & Family & Studies & Tourism & Other \\
\hline \multirow[t]{2}{*}{ Treatment } & 0.002 & $0.024^{* *}$ & $0.022^{* *}$ & -0.002 & 0.001 & -0.001 \\
\hline & $(0.009)$ & $(0.010)$ & $(0.008)$ & $(0.004)$ & $(0.003)$ & $(0.002)$ \\
\hline Extended controls & Yes & Yes & Yes & Yes & Yes & Yes \\
\hline Island FE & Yes & Yes & Yes & Yes & Yes & Yes \\
\hline Control mean & 0.040 & 0.047 & 0.030 & 0.008 & 0.005 & 0.002 \\
\hline Observations & 2163 & 2163 & 2163 & 2163 & 2163 & 2163 \\
\hline
\end{tabular}

Notes: Robust standard errors are in parentheses. ${ }^{* * *} \mathrm{p}<0.01,{ }^{* *} \mathrm{p}<0.05,{ }^{*} \mathrm{p}<0.1$.

Table A13: Summary statistics on remittances sent by migration reason

\begin{tabular}{|c|c|c|c|c|}
\hline & \multicolumn{3}{|c|}{ Remittances } & \multirow{3}{*}{$\mathrm{N}$} \\
\hline & \multirow[t]{2}{*}{ Dummy } & \multicolumn{2}{|c|}{ Amount sent } & \\
\hline & & (All) & (if $\mathrm{D}=1$ ) & \\
\hline Economic & 0.44 & 5.00 & 11.49 & 62 \\
\hline Health & 0.13 & 1.24 & 9.83 & 79 \\
\hline Family & 0.24 & 2.79 & 11.49 & 70 \\
\hline Studies & 0.14 & 0.87 & 6.10 & 14 \\
\hline Tourism & 0.17 & 1.92 & 11.51 & 6 \\
\hline Other & 0.00 & & & 4 \\
\hline Total & 0.23 & 2.58 & 11.16 & 208 \\
\hline
\end{tabular}

Notes: An inverse hyperbolic sine (IHS) transformation has been applied to all remittances amount. The sample is restricted to Mayotte migrants. We do not have information on remittances sent by return migrants during their time in Mayotte.

Heterogeneous effects We examine heterogeneity in the effect by baseline characteristics. In Table A14, we analyze whether the effect varies with (i) the willingness 
to migrate, (ii) the number of rounds of CFW received, (iii) the number of workingage adults in the household, (iv) the total consumption per adult equivalent, (v) the schooling of the household head, and (vi) a dummy indicating whether the household has at least one child in Mayotte (a measure of migration network) ${ }^{42}$

Because of the financial constraints highlighted above, we expect the effect to increase with household willingness to migrate and the number of CFW received, and decrease with consumption. The mediating effect of the number of working age adults is more ambiguous. The more working-age adults in the household, the less binding the labor requirement of CFW opportunities. However, the marginal effect of cash received may be smaller in larger households. Similarly, heterogeneity in treatment effects with respect to the migration network could go either way. On the one hand, the treatment could complement network effects if liquidity and risk constraints are too binding even in the presence of relatives in Mayotte. On the other hand, the treatment may only affect households with no connections in Mayotte if aspiring migrants have already seen their liquidity and risk constraints alleviated by their relatives in Mayotte.

Table A14: Heteregeneous Effects

\begin{tabular}{lcccccc}
\hline \hline & \multicolumn{5}{c}{ Migration (excluding returns) } \\
\cline { 2 - 7 } & $(1)$ & $(2)$ & $(3)$ & $(4)$ & $(5)$ & $(6)$ \\
\hline Treatment & $0.023^{*}$ & -0.034 & 0.029 & 0.042 & $0.028^{*}$ & $0.031^{* * *}$ \\
& $(0.013)$ & $(0.042)$ & $(0.024)$ & $(0.091)$ & $(0.015)$ & $(0.012)$ \\
Treatment x Willing to migrate & 0.025 & & & & & \\
& $(0.033)$ & & & & & \\
Treatment x CFW rounds (N) & & 0.013 & & & & \\
& & $(0.009)$ & & & & \\
Treatment x Working age adults (N) & & & -0.001 & & & \\
& & & $(0.008)$ & & & \\
Treatment x Consumption & & & & -0.002 & & \\
& & & & $(0.012)$ & & \\
Treatment x Schooling & & & & & 0.000 & \\
& & & & & & $-0.013)$ \\
Treatment x Migration network & & & & & & $(0.046)$ \\
\hline Extended controls & & & & & & \\
Island FE & Yes & Yes & Yes & Yes & Yes & Yes \\
Control mean & Yes & Yes & Yes & Yes & Yes & Yes \\
Observations & 0.078 & 0.078 & 0.078 & 0.078 & 0.078 & 0.078 \\
\hline
\end{tabular}

Notes: Each column refers to a different LPM estimate using equation [3]. Robust standard errors are in parentheses. ${ }^{* *} \mathrm{p}<0.01,{ }^{* *} \mathrm{p}<0.05,{ }^{*} \mathrm{p}<0.1$.

The sign of the interaction terms are in line with expectations, but not significant at conventional significance levels. It seems that the effect is stronger for households willing to migrate and receiving more CFW rounds, and lower for more wealthy households. The number of working-age adults and the migration network do not appear to condition the effect. We explored the presence of potential non-linearities using a

\footnotetext{
${ }^{42}$ The analysis of heterogeneous treatment effects by network was not specified in our pre-analysis. We thank an anonymous referee for highlighting the relevance of this supplementary analysis.
} 
quadratic interaction term but the results show no effects.

We investigate heterogeneous effects more comprehensively by implementing the endogenous stratification method, a three-step procedure which allows to assess how different groups are affected by the treatment. First, using control households, we regress the outcome variable (migration to Mayotte) on the baseline characteristics highlighted in Table 1. We then use the fitted coefficients to predict migration in the absence of treatment for both the treatment and control groups. Finally, we split the households into different groups on the basis of their predicted migration values and estimate treatment effects across these groups. ${ }^{43}$ The results are presented in Table A15.

Table A15: Endogenous stratification

\begin{tabular}{|c|c|c|c|c|c|c|}
\hline & \multicolumn{2}{|c|}{ Household } & \multicolumn{4}{|c|}{ Individual } \\
\hline & \multirow{2}{*}{$\begin{array}{c}\text { Migration } \\
\text { (excl. returns) } \\
(1)\end{array}$} & \multirow{2}{*}{$\begin{array}{c}\text { Migration } \\
\text { (incl. returns) } \\
(2)\end{array}$} & \multicolumn{2}{|c|}{$\begin{array}{l}\text { Migration } \\
\text { (excl. returns) }\end{array}$} & \multicolumn{2}{|c|}{$\begin{array}{c}\text { Migration } \\
\text { (incl. returns) }\end{array}$} \\
\hline & & & (3) & $(4)$ & $(5)$ & $(6)$ \\
\hline \multicolumn{7}{|l|}{ Low predicted migration } \\
\hline Treatment & 0.021 & 0.000 & 0.001 & $0.006^{* *}$ & 0.002 & 0.005 \\
\hline SE & (0.014) & $(0.022)$ & (0.003) & (0.003) & (0.003) & $(0.004)$ \\
\hline Control mean & 0.018 & 0.063 & 0.011 & 0.007 & 0.015 & 0.011 \\
\hline \multicolumn{7}{|c|}{ Medium predicted migration } \\
\hline Treatment & 0.023 & $0.064^{* *}$ & & -0.002 & & 0.003 \\
\hline SE & $(0.022)$ & $(0.028)$ & & $(0.005)$ & & $(0.005)$ \\
\hline Control mean & 0.066 & 0.090 & & 0.014 & & 0.020 \\
\hline \multicolumn{7}{|c|}{ High predicted migration } \\
\hline Treatment & 0.041 & 0.037 & $0.011^{* * *}$ & $0.014^{* * *}$ & $0.016^{* * *}$ & $0.018^{* * *}$ \\
\hline SE & $(0.031)$ & $(0.037)$ & $(0.004)$ & $(0.005)$ & $(0.005)$ & $(0.006)$ \\
\hline Control mean & 0.152 & 0.236 & 0.019 & 0.023 & 0.032 & 0.040 \\
\hline Number of groups & 3 & 3 & 2 & 3 & 2 & 3 \\
\hline \multicolumn{7}{|l|}{ Predictors: } \\
\hline Extended controls & Yes & Yes & No & No & No & No \\
\hline Island FE & Yes & Yes & Yes & Yes & Yes & Yes \\
\hline Individual controls & No & No & Yes & Yes & Yes & Yes \\
\hline Observations & 2181 & 2181 & 14288 & 14288 & 14288 & 14288 \\
\hline
\end{tabular}

Notes: Using the leave-one-out estimation procedure. Standard errors in parentheses are bootstrapped (1,000 repetitions). ${ }^{* * *} \mathrm{p}<0.01,{ }^{* *} \mathrm{p}<0.05,{ }^{*} \mathrm{p}<0.1$.

${ }^{43}$ The fitted model is estimated excluding the observation itself to avoid bias (Abadie et al. 2018 . We used the estrat Stata command with the leave-one-out option which automates the procedure. 